\title{
O CAMPO TÉRMICO NO PERÍMETRO URBANO DE PONTE NOVA-MG (ZONA DA MATA MINEIRA), EM SITUAÇÕES SAZONAIS DE VERÃO E INVERNO, NO ANO DE 2017
}

\author{
ALLOCCA, Rodson de Andrade - rodson.ufv@gmail.com \\ Universidade Federal do Espirito Santo / UFES \\ FIALHO, Edson Soares - fialho@ufv.br \\ Universidade Federal de Viçosa / UFV
}

\begin{abstract}
RESUMO: Recentemente, o clima das cidades de pequeno porte vem sendo objeto de estudos em Geografia. Inseridos nesta perspectiva, esta pesquisa visa investigar o campo térmico, na área urbana de Ponte Nova-MG, com intuito de identificar como se relacionam os fatores naturais (relevo, orientação de encosta, altimetria etc.) com os fatores urbanos (SVF, densidade de população, usos da terra etc.). Para tanto, foi estruturada e utilizada uma rede de monitoramento das temperaturas do ar, baseada em pontos fixos de coleta de dados, e também na técnica de transects móveis. A espacialização do campo térmico apresentou diferenças no gradiente de temperatura do ar para os dois episódios de coleta de dados, verão e inverno de 2017. No episódio de inverno foi registrada a maior diferença térmica, $13,8^{\circ} \mathrm{C}$. Os resultados foram discutidos a partir de uma busca da correlação entre os fatores climáticos e a temperatura do ar registrada. Concluiu-se que o clima local é fortemente influenciado pelo relevo do sítio urbano e em menor parte pelo fator urbano.
\end{abstract}

Palavras-chave: Campo térmico, Variação sazonal, Ponte Nova-MG.

THE THERMAL FIELD IN THE URBAN PERIMETER OF PONTE NOVA-MG (MATA MINEIRA REGION), IN SUMMER SUMMER AND WINTER SITUATIONS, IN THE YEAR OF 2017.

\begin{abstract}
The climate of small cities has been the subject of studies in Geography. Inserted in perspective, geographically aims to investigate the thermal field, in the urban area of Ponte Nova-MG, with the purpose of identifying how to relate to natural factors (relief, slope orientation, altimetry, etc.) of population, land uses etc.). For this purpose, a temperature monitoring network was built and used, based on fixed points of data collection and also on the technique of mobile transects. The thermal field spatialisation showed differences in the air temperature gradient for the two data collection episodes, summer and winter of 2017. In the winter episode the greatest thermal difference was recorded, $13.8^{\circ} \mathrm{C}$. The results were discussed from a search of the correlation between the climatic factors and the air temperature recorded. It was concluded that the local climate is strongly influenced by the relief of the urban site and to a lesser extent by the urban factor.
\end{abstract}

Keywords: Thermal field, Seasonal variation, Ponte Nova-MG. 


\section{INTRODUÇÃO}

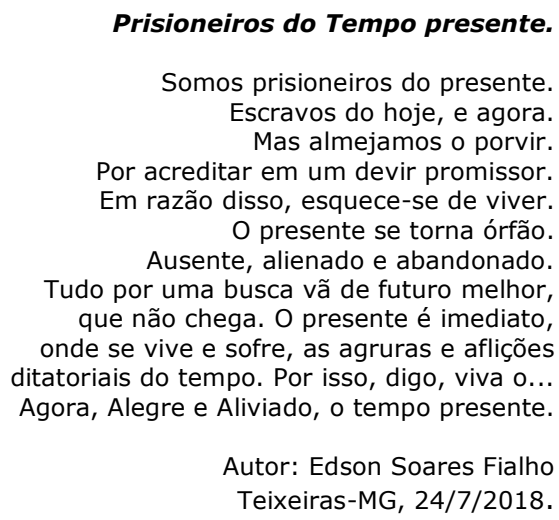

No Brasil, o estudo do clima da cidade priorizou, inicialmente, as cidades de grande porte, como Salvador (Sampaio, 1981), São Paulo (Lombardo, 1985) e Rio de Janeiro (Brandão, 1996). Ao longo da década de 1990, as cidades de médio porte foram sendo valorizadas. $E$, mais recentemente, as cidades de pequeno porte vêm sendo objeto de estudos em Geografia, como Fresca (2010), Moreira Júnior (2014), Rigon e Sant'Ana (2013), dentre outros, assim como da Climatologia.

Os processos de crescimento urbano exercem, em maior ou menor grau, influência no comportamento das variáveis climáticas e ambientais. Segundo Amorim (2010, p. 73), "[...] as cidades muito embora não ocupem grandes extensões territoriais, são elas as maiores transformadoras do meio natural. 0 crescimento urbano, na maioria dos casos, não acompanhou a dinâmica da natureza, resultando no comprometimento da qualidade desses ambientes.".

Os estudos sobre clima urbano subsidiam o planejamento e, ao mesmo tempo, podem indicar ações necessárias para que seja propiciada uma condição de maior harmonia entre as estruturas antrópicas e o ambiente natural, pois, segundo Amorim (2010, p, 88), "O estudo de clima urbano, além de quantificação das alterações detectadas, torna fundamental uma análise geográfica do fenômeno, ou seja, estabelece relações entre os dados mensurados e os elementos componentes da cidade.". O planejamento urbano é, por seu caráter, uma temática que requer maior empenho por parte da gestão municipal e dentro do escopo das pesquisas relacionadas ao assunto. Sendo assim, os estudos sobre clima urbano tornam-se necessários, sobretudo por indicarem medidas que sejam adequadas à garantia de melhores condições para a vida e para o conforto dos habitantes.

Nos estudos de clima urbano desenvolvidos em terras brasileiras, dois laboratórios de pesquisa encontram-se na vanguarda e merecem citação, o GAIA e o Laboclima, ambos pertencentes aos respectivos Departamentos de Geografia da Unesp-Presidente Prudente e da Universidade Federal do Paraná (UFPR). O primeiro investigando as cidades do oeste paulista e centro-oeste brasileiro, enquanto o segundo investigando o Brasil subtropical. E outros agora surgindo, como o Laboratório de Climatologia da UFSM, o Laboratório de Geografia Física da UFGD e o Laboratório de Climatologia da UFPE.

Sobre a mesma perspectiva, o Laboratório de Biogeografia e Climatologia (Bioclima) do Departamento de Geografia da Universidade Federal de Viçosa 
(UFV), através de seus pesquisadores, busca investigar as cidades de pequeno porte da Zona da Mata Mineira, que se encontra em um sítio de planalto dissecado convergente. A primeira investigação recaiu sobre Viçosa-MG (FIALHO, 2009, 2015; FIALHO; QUINA, 2017; QUINA, 2015, FERNANDES, 2015; FERNANDES et al., 2017) e ampliando os horizontes para municípios vizinhos como Cajuri-MG (FIALHO et al., 2016) e também outros estados, como o Espírito Santo, nos estudos sobre os municípios de Vitória (CORREIA, 2014) e Serra (OLIVEIRA et al., 2017).

E agora, esta pesquisa visa investigar o campo térmico na área urbana de Ponte Nova-MG, com intuito de identificar como se relacionam os fatores naturais (relevo, orientação de encosta, altimetria etc.) com os fatores urbanos (SVF, densidade de população, usos da terra etc.).

\section{2.ÁREA DE ESTUDO}

O município de Ponte Nova (Figura 1) apresenta uma área de aproximadamente $470 \mathrm{~km}^{2}$ (IBGE, 2015), está localizado nas coordenadas $20^{\circ}$ 24' 59" S e 420 54' 31" W, a uma distância aproximada de duzentos quilômetros da capital do estado de Minas Gerais, Belo Horizonte, na Mesorregião da Zona da Mata, em sua porção Norte.

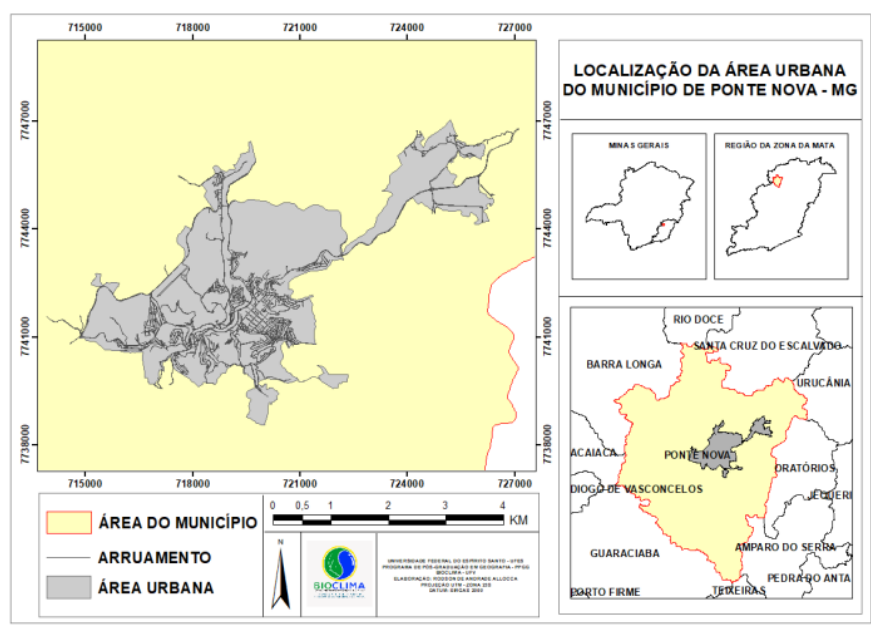

Figura 1 - localização do município de Ponte Nova fonte: elaborado pelo autor.

Situa-se em região de relevo acidentado (Figura 2), classificado como Domínio Morfoclimático dos Mares de Morros Florestados (AB'SABER, 2003). Tal relevo apresenta formas bastante dissecadas por ação fluvial, com presença de inúmeras colinas em formato de "meia laranja" e fundos de vales de largura variável (PRADO et al., 2018; ALVES, 2015; ROCHA e FIALHO, 2010; MARCHI et al., 2005; NUNES et al., 2001). 


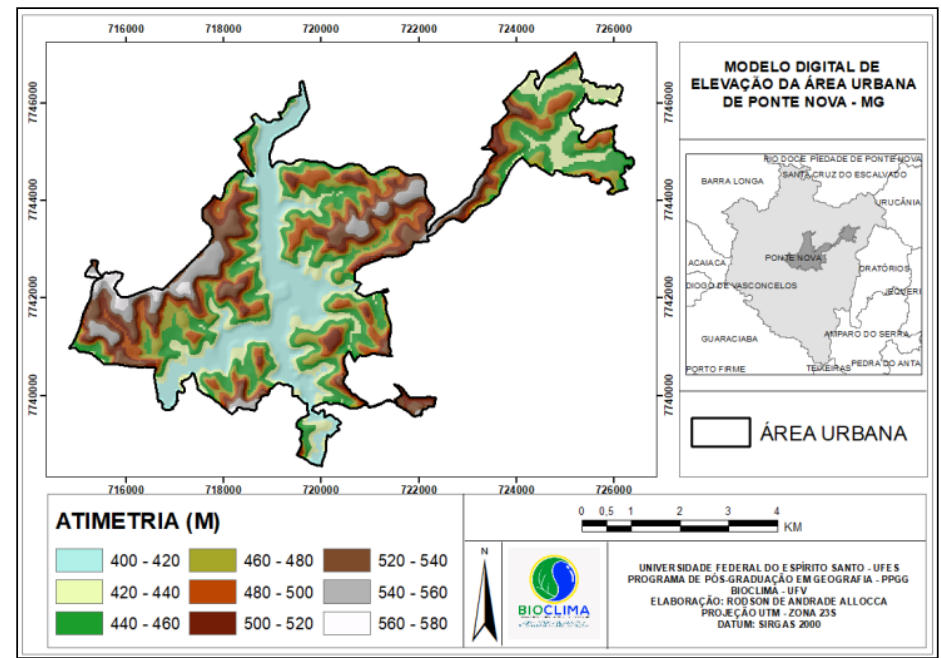

Figura 2 - modelo digital de elevação da área urbana do município de Ponte Nova - MG. Fonte: elaborado pelo autor.

A área urbana do município é cortada pelo rio Piranga (sentido SW-N) e, pelo ribeirão Vau-Açú, um de seus tributários (sentido S-N). A estrutura urbana, em seu processo de desenvolvimento, ocupa áreas do fundo do vale, espraiando-se para as encostas dos morros em seu entorno que apresentam declividade e orientação de vertentes variadas. As cotas altimétricas na área urbana não ultrapassam um intervalo de duzentos metros e a largura do vale apresenta diferentes amplitudes ao longo de seu traçado.

O município está situado numa área onde ocorrem dois tipos climáticos: Cwa - úmido de verões quentes e o tipo Aw - semiúmido, de acordo com a classificação climática de Köppen, onde as médias térmicas anuais estão entre $24^{\circ} \mathrm{C}$ e $33^{\circ} \mathrm{C}$ (NATALI, 1999 apud MARCHI et al., 2005).

Em termos populacionais, na perspectiva dos estudos de clima urbano, é considerado de pequeno porte (FIALHO, 2009), contudo sua população urbana corresponde, segundo dados do último censo demográfico, a aproximadamente $90 \%$ do total populacional residente no município (IBGE, 2010) e sua distribuição faz com que em algumas áreas ocorram elevadas taxas de densidade demográfica.

A partir de uma análise da evolução da população, pode ser percebido um aumento do número de habitantes nos últimos anos (Tabela 1), fato que aponta para uma perspectiva de expansão de funções e da própria mancha urbana e, assim, endossando a necessidade de planejamento para que os usos da terra na área urbana (Figura 3) possam ser geridos de modo que a preocupação com a saúde ambiental e o conforto populacional estejam sendo considerados perante os interesses norteadores do processo de expansão.

O município, num âmbito microrregional, é um importante centro de comércio e serviços, recebendo um fluxo diário de pessoas vindas de municípios próximos. Justificado por esse contexto, o trabalho aqui proposto buscará responder à seguinte problemática: Qual a influência dos fatores geourbanos e 
geoecológicos no comportamento do campo térmico na área urbana ${ }^{1}$ do município de Ponte Nova, MG?

Tabela 1 - Evolução da população do município de Ponte Nova - MG.

\begin{tabular}{|cc|}
\hline ANO & NÚMERO DE HABITANTES \\
\hline 1991 & 56.678 \\
\hline 1997 & 58.361 \\
\hline 2000 & 55.303 \\
\hline 2007 & 55.687 \\
\hline 2010 & 57.390 \\
\hline $2016^{*}$ (Estimada) & 60.188 \\
\hline
\end{tabular}

Fonte: IBGE - censo demográfico 1991, contagem populacional 1996, censo demográfico 2000, contagem populacional 2007 e censo demográfico 2010 (adaptado). Organizado pelo autor.

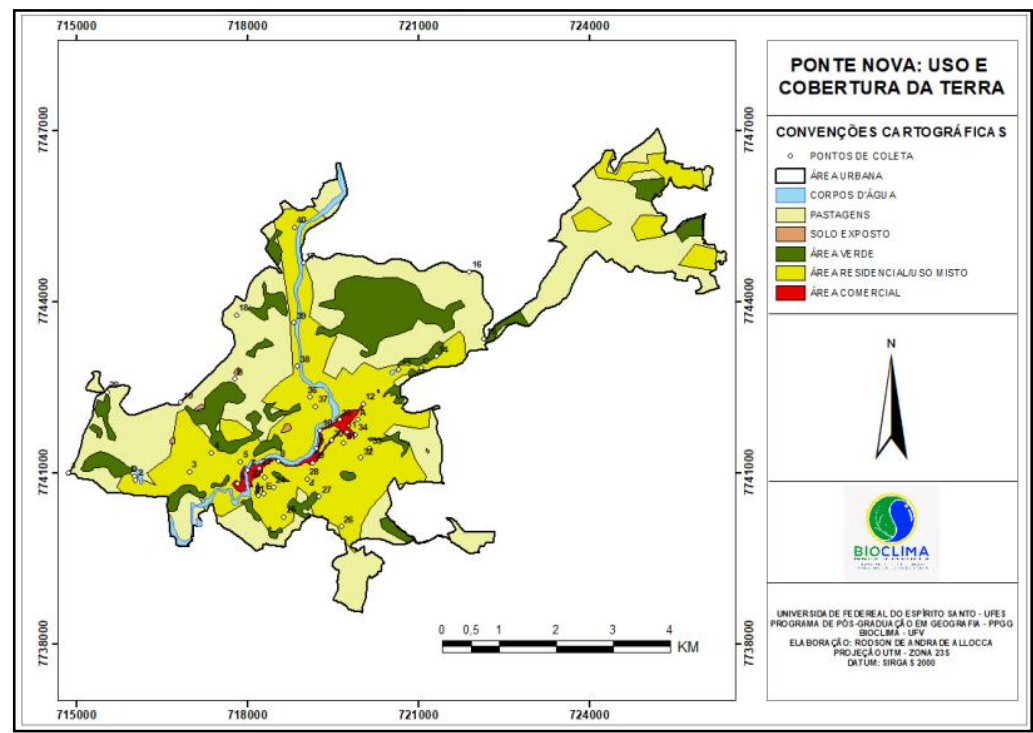

Figura 3 - Uso e cobertura da terra na área urbana de Ponte Nova-MG. Fonte: elaborado pelo autor.

\section{MATERIAL E MÉTODOS}

O município de Ponte Nova é desprovido de uma estação meteorológica oficial. Para o desenvolvimento da pesquisa, foi fundamental a criação de uma rede de monitoramento de dados estruturada a partir da instalação de dataloggers do tipo HOBO-U-012, em miniabrigos de policloreto de vinila (PVC) baseados na proposta de Lopes e Jardim (2012) e distribuídos em 5 pontos fixos de coleta na área urbana. Antes da instalação dos sensores digitais datalogger, foi realizado a aferição dos equipamentos, utilizando como referência a estação meteorológica do Instituto Nacional de Meteorologia (INMET), situada no campus da Universidade Federal de Viçosa (UFV).

\footnotetext{
${ }^{1} \mathrm{Na}$ pesquisa não foram considerados os distritos municipais. Apenas a área urbana associada à sede municipal foi pesquisada.
} 
$\mathrm{Na}$ aquisição dos dados de temperatura do ar na área urbana do município de Ponte Nova-MG, além do uso de uma rede de pontos fixos de coleta, optou-se pelo uso da técnica de transects móveis que consiste no estabelecimento de uma malha de pontos para coleta de dados, distribuídos ao longo da área selecionada para o desenvolvimento das análises, tendo como base alguns dos procedimentos realizados por Fialho (2009).

Foram estabelecidos, dentro da área da pesquisa, 40 pontos amostrais organizados em dois trajetos distintos. Com o uso da técnica de transects móveis associada aos levantamentos realizados nos pontos fixos, foi possível uma ampliação da capacidade de monitoramento dos dados térmicos. Na Figura 4 é possível visualizar a localização de todos os pontos (fixos e móveis), assim como os trajetos realizados nos transects móveis. Ressalta-se que, para uma melhor visualização, foi feita uma adaptação na representação da área urbana, concentrando o enfoque na espacialização mais próxima da rede de monitoramento, portanto, foi suprimida a porção Nordeste da área urbana, onde não haviam pontos de coleta de dados.

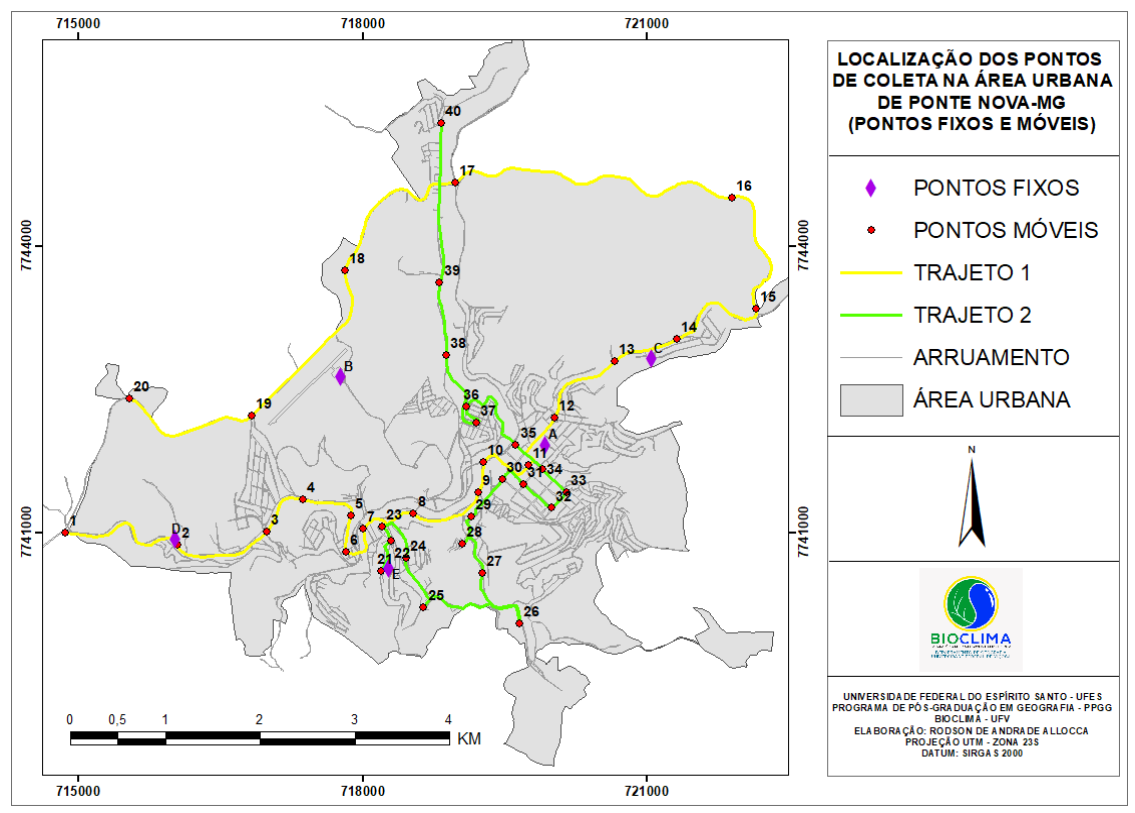

Figura 4 - Pontos Móveis (trajeto 1 e 2) e pontos fixos. Fonte 1: elaborado pelo autor.

Para a realização dos transects móveis foi utilizado um termohigrômetro digital modelo Minipa MT-241, abrigado em uma estrutura de PVC e acoplado em veículo automotor, adotando o mesmo procedimento realizado por Fialho (2009).

As coletas de dados foram realizadas em três horários distintos (09h00min, $15 \mathrm{~h} 00 \mathrm{~min}$ e às $18 \mathrm{~h} 00 \mathrm{~min})$, selecionados com base na proposta de variação diuturna da temperatura do ar (MENDONÇA E DANNI-OLIVEIRA, 2007; p.53).

Os trabalhos de Fialho (2009) e Correa (2014) apresentaram propostas semelhantes no que diz respeito aos horários de coleta. Contudo, para a coleta realizada na área urbana de Ponte Nova, foi feita uma adaptação em relação ao terceiro horário, antecipado para às $18 \mathrm{~h} 00 \mathrm{~min}$ em função de questões de 
segurança. As informações sobre cada episódio de coleta estão organizadas na Tabela 2.

Tabela 2 - Datas das coletas móveis, estação do ano e tempo de duração.

\begin{tabular}{|c|c|c|c|c|c|c|}
\hline Data & $\begin{array}{l}\text { Estação } \\
\text { do Ano }\end{array}$ & Período & Trajeto & $\begin{array}{c}\text { Horário } \\
\text { Inicial }\end{array}$ & $\begin{array}{c}\text { Horário } \\
\text { Final }\end{array}$ & $\begin{array}{c}\text { Tempo total } \\
\text { decorrido }\end{array}$ \\
\hline \multirow[t]{6}{*}{$17 / 03 / 2017$} & \multirow[t]{6}{*}{ Verão } & \multirow[t]{2}{*}{ Manhã } & 1 & 09:00 & $10: 14$ & \multirow[t]{2}{*}{$02 \mathrm{~h}$ e $29 \mathrm{~min}$} \\
\hline & & & 2 & $10: 26$ & $11: 29$ & \\
\hline & & \multirow[t]{2}{*}{ Tarde } & 1 & $15: 00$ & $15: 58$ & \multirow[t]{2}{*}{$02 \mathrm{~h}$ e $10 \mathrm{~min}$} \\
\hline & & & 2 & $16: 15$ & $17: 10$ & \\
\hline & & \multirow[t]{2}{*}{ Noite } & 1 & $18: 00$ & $18: 46$ & \multirow[t]{2}{*}{$02 \mathrm{~h}$} \\
\hline & & & 2 & $18: 58$ & $20: 00$ & \\
\hline \multirow[t]{6}{*}{$27 / 07 / 2017$} & \multirow[t]{6}{*}{ Inverno } & \multirow[t]{2}{*}{ Manhã } & 1 & 09:00 & $10: 04$ & \multirow[t]{2}{*}{$02 \mathrm{~h}$ e $10 \mathrm{~min}$} \\
\hline & & & 2 & $10: 14$ & $11: 10$ & \\
\hline & & \multirow[t]{2}{*}{ Tarde } & 1 & $15: 00$ & $16: 02$ & \multirow[t]{2}{*}{$02 \mathrm{~h}$ e $08 \mathrm{~min}$} \\
\hline & & & 2 & $16: 16$ & $17: 08$ & \\
\hline & & \multirow[t]{2}{*}{ Noite } & 1 & $18: 00$ & $18: 57$ & \multirow[t]{2}{*}{ 01h e $57 \mathrm{~min}$} \\
\hline & & & 2 & $19: 08$ & $19: 57$ & \\
\hline
\end{tabular}

Fonte: elaborado pelo autor.

Muitos trabalhos, que se utilizam da técnica de transects móveis, realizam as coletas em intervalos temporais que não ultrapassam o limite máximo de uma hora, contudo a duração da coleta completa (Trajetos 1 e 2), em cada episódio, variou entre $01 \mathrm{~h}$ e $57 \mathrm{~min}$ (coleta mais rápida) e $02 \mathrm{~h}$ e $29 \mathrm{~min}$ (coleta mais lenta), fato que gerou uma defasagem temporal durante a coleta dos dados.

No trabalho de Steffens et al. (2001), que investiga a ocorrência da ilha de calor durante o verão na cidade de Temuco, Chile, o tempo de realização dos transects foi de aproximadamente duas horas. Nesse caso, os autores submeteram os dados coletados a uma correção, tendo como referência a variação linear da temperatura de uma estação fixa. No estudo da ilha de calor na cidade de Alicante, Espanha, desenvolvido por Martínez (2014), as coletas de dados, realizadas em dez episódios através da técnica de transects móveis, tiveram uma duração média de $01 \mathrm{~h}$ e $56 \mathrm{~min}$. Por esse motivo, considerando as experiências supracitadas, foi proposto um método experimental de correção dos dados coletados, para que nos registros dos valores térmicos pudesse ser compensada a defasagem temporal decorrente do deslocamento entre os pontos de coleta.

\subsection{MÉTODO DE CORREÇÃO DOS DADOS}

Na observação do campo térmico proposto por essa pesquisa admitiu-se, como procedimento ideal, que os registros dos dados fossem efetuados simultaneamente pois, trata-se de uma comparação entre os registros em diferentes pontos da cidade. Nesse sentido, seria necessária uma estrutura complexa para que isso ocorresse em todos os pontos amostrais. Por não dispor de uma equipe numerosa e equipamentos suficientes, a utilização dos transects móveis foi adotada por representar uma alternativa mais viável no levantamento dos dados. 
Inevitavelmente, entre o registro efetuado no primeiro e no último ponto do transect, ocorre uma defasagem temporal que pode representar também uma variação nas condições da temperatura do ar. Desse modo, com o intuito de comparar os dados para um mesmo horário de registro, fez-se necessário submeter os valores registrados na coleta móvel a uma correção, com base na variação da temperatura do ar ocorrida durante a realização de cada etapa dos transects.

A correção dos dados foi realizada por um método experimental, elaborado pelo autor, adaptado da proposta de Martinez (2014). No método proposto, os pontos fixos, instalados na área da pesquisa, foram utilizados como referências para observação da variação térmica registrada durante o tempo de execução dos transects móveis.

Com o intuito de minimizar a superestimação ou subestimação dos dados, foram configurados, a partir dos pontos fixos, setores de correção, conforme pode ser observado na Figura 5. Cada ponto fixo foi elencado para servir de referência na correção dos pontos móveis dentro de um raio de, aproximadamente, dois quilômetros e meio. Esse procedimento foi adotado para que, na correção, os pontos móveis fossem corrigidos pelo ponto fixo alocado numa área com características geourbanas e geoecológicas semelhantes, considerando que este fator, embora não seja o único determinante, possa ter influência no comportamento térmico.

Para a correção dos dados, utilizou-se a seguinte equação:

$$
T=t_{s c} \pm\left(t_{d} \times \frac{\Delta t}{60 \mathrm{~min}}\right)
$$

Sendo: $T$ (temperatura corrigida); $t_{s c}$ (temperatura sem correção); $t_{d}$ (tempo decorrido); $\frac{\Delta t}{60 \min }$ (variação de temperatura por minuto no ponto de controle).

Para cada setor de correção, foram utilizados na equação dados do ponto de referência específico do setor, ou seja, em cada setor os valores utilizados na correção foram diferentes, específicos.

A variação da temperatura do ar foi observada em intervalos horários em cada ponto de controle. Para cada hora foi calculada a variação da temperatura do ar por minuto e para todos os valores mensurados dentro do intervalo horário, utilizada esta variação por minuto como constante na correção dos dados. 


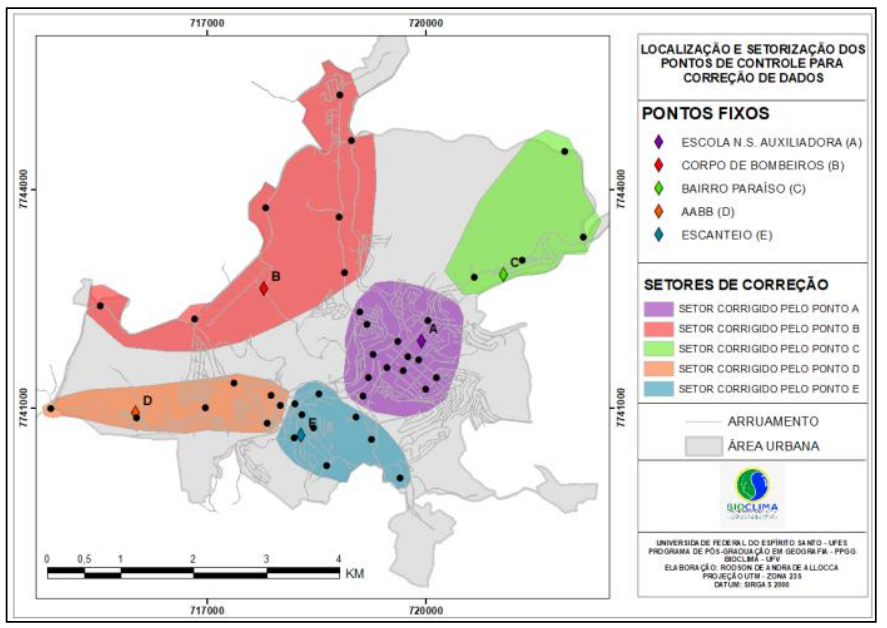

Figura 5 - Setorização dos pontos de controle para correção dos dados. Fonte: elaborado pelo autor.

Para uma melhor compreensão, segue uma exemplificação do uso do método a partir de dados hipotéticos. Imaginemos que o no ponto 9 do transect móvel foi registrada a temperatura de $32^{\circ} \mathrm{C}$, às $09 \mathrm{~h} 20 \mathrm{~min}$. Para sua correção, foi apurado que no seu ponto fixo de controle, entre 09h00min e 10h00min, houve uma variação positiva da temperatura de $0,02^{\circ} \mathrm{C} / \mathrm{min}$. Então, a partir da aplicação da equação, temos:

$$
T=32-(20 \times 0,02), \log , \quad T=31,6^{\circ} \mathrm{C} .
$$

O procedimento faz a compensação das diferenças nos valores de temperatura do ar, corrigindo a defasagem. Pois, quando foi observado um aquecimento do ar no intervalo horário, diminuiu-se da temperatura do ar registrada sem correção o produto do tempo decorrido pela variação da temperatura do ar por minuto. Nos intervalos horários em que foi observado resfriamento atmosférico, acrescentou-se ao valor da temperatura do ar sem correção o valor do produto do tempo decorrido pela variação da temperatura do ar por minuto.

Nos casos em que a coleta em determinado ponto aconteceu após o intervalo da primeira hora, foi considerada a variação de temperatura do ar na primeira hora e estabelecida uma nova constante de variação por minuto, com base nas alterações de temperatura do ar registradas no ponto fixo na hora subsequente.

\subsection{SKY VIEW FACTOR (SVF)}

Nos estudos de clima urbano, uma análise abrangente dos fatores que contribuem para a configuração espacial do campo térmico e favoreça sua compreensão é fundamental.

Neste sentido, insere-se uma análise da geometria urbana, através da técnica de Sky View Factor (SVF) como um parâmetro importante. Segundo Chapman (2007), os obstáculos presentes nas áreas urbanas influenciam na 
dinâmica de entrada e dispersão da radiação solar, alterando o comportamento da temperatura.

Para o levantamento dos dados de SVF, foi utilizada uma câmera fotográfica com lente angular olho de peixe para registro das imagens hemisféricas em cada ponto de coleta de dados de temperatura do ar utilizados na área da pesquisa (Figura 6 ). Os registros fotográficos foram obtidos segundo os procedimentos propostos por Collischonn e Ferreira (2015) e submetidos ao software RayMan $1.2^{2}$ para que fossem calculados o do fator visão do céu em cada ponto. Como referência, para a classificação dos valores do SVF (Tabela 3), foi considerada a proposta de Collischonn e Ferreira (2015), em que:

Tabela 3 - classificação dos valores de svf

\begin{tabular}{|c|c|}
\hline Classificação & Intervalo de valor do Sky View Factor \\
\hline Alta Obstrução & 0 a 0,400 \\
\hline Obstrução Moderada & 0,401 a 0,700 \\
\hline Baixa Obstrução & 0,701 a 1 \\
\hline
\end{tabular}

Fonte: adaptado de Collischonn e Ferreira (2015). Organizado pelo autor.

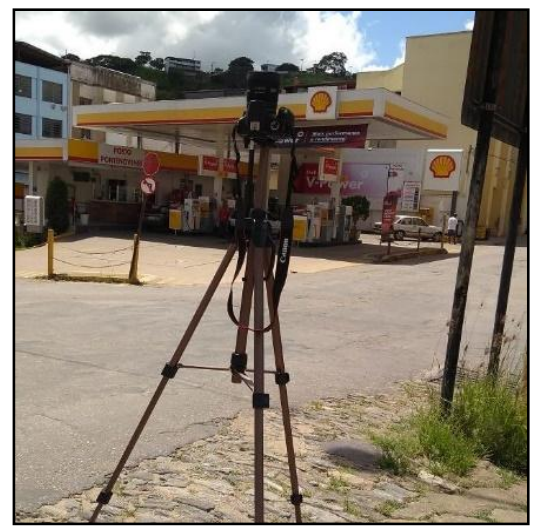

Figura 6 - Câmera fotográfica com lente angular para registro das imagens hemisféricas. Fonte: registro fotográfico efetuado pelo autor em janeiro de 2018.

\subsection{PROCEDIMENTOS DE ANÁLISE DA RELAÇÃO ENTRE OS FATORES CLIMÁTICOS E A TEMPERATURA DO AR}

Considerando a população dos dados apurados, foram identificados os valores mais representativos baseados nos registros de temperatura do ar na área urbana $e$, na perspectiva de se compreender a influência dos diferentes fatores no comportamento do campo térmico, foram estabelecidas análises descritivas, além de análises estatísticas, através do método de Correlação Linear de Pearson, entre os valores térmicos e os fatores climáticos quantificados na realização da pesquisa.

\footnotetext{
${ }^{2}$ Programa desenvolvido por Andreas Matzarakis, que possibilita o cálculo do fator de visão do céu com base na geometria local
} 
Como parâmetro para a análise estatística adotou-se a mesma classificação dos coeficientes de correlação linear (Tabela 4) utilizada por Paulo (2017) e adaptada de Cavalcante (2003).

Tabela 4 - Tabela de classificação do coeficiente de correlação linear de Pearson e coeficiente de determinação.

\begin{tabular}{|c|c|c|c|c|c|c|}
\hline CLASSIFICAÇÃo & NULA & FRACA & MÉDIA & FORTE & FORTÍSSIMA & PERFEITA \\
\hline $\begin{array}{c}\text { Coeficiente de } \\
\text { Pearson }(r)\end{array}$ & 0 & $0,00---0,30$ & $0,30---0,60$ & $0,60---$ & $0,90---0,99$ & 1 \\
& & & & 0,90 & & \\
\hline $\begin{array}{c}\text { Coeficiente de } \\
\text { Determinação } \\
\left(R^{2}\right)\end{array}$ & 0 & $0,00---0,09$ & $0,09---0,36$ & $0,36---$ & $0,81---0,99$ & 1 \\
& & & & 0,81 & & \\
\hline
\end{tabular}

Fonte: Cavalcante (2003 apud Paulo, 2017). Adaptado.

\section{RESULTADOS E DISCUSSÕES}

\subsection{EPISÓDIO DE VERÃO (18/03/2017)}

\section{Síntese da condição sinótica}

No dia 18/03 foi observada a ocorrência de uma elevação abrupta da temperatura do ar em todos os horários (9h00min, 15h00min e 18h00min). Esse processo está associado a um aquecimento pré frontal. Os ventos do quadrante sudoeste trouxeram para a região a Massa Polar Atlântica ( $\mathrm{mPa}$ ), que atuaou sobre o município nos dias subsequentes, ao longo da semana.

\section{Análise do campo térmico às 09h00min}

A coleta de dados realizada durante o período matinal revelou a ocorrência de uma variação térmica de $5,7^{\circ} \mathrm{C}$ dentro da área urbana de Ponte Nova. A mínima temperatura do ar registrada foi de $22,9^{\circ} \mathrm{C}$ no Ponto 40 e a máxima de $28,6^{\circ} \mathrm{C}$ no Ponto 1 .

No mapeamento do campo térmico, conforme pode ser observado na Figura 7, nota-se a ocorrência de núcleos com temperaturas do ar mais baixas ao longo do eixo Sul/Norte.

Nas análises, foram selecionados os pontos mais representativos considerando os maiores e menores valores de temperatura do ar registrados no horário da realização da coleta (Figura 8). Os Pontos 27, 28, 35, 37, 38 e 39 destacam-se por apresentarem temperaturas do ar compreendidas no intervalo entre $23^{\circ}$ e $23,9^{\circ} \mathrm{C}$, representando, juntamente com o Ponto $40\left(22,9^{\circ} \mathrm{C}\right)$, as menores temperaturas do ar registradas para o horário. 


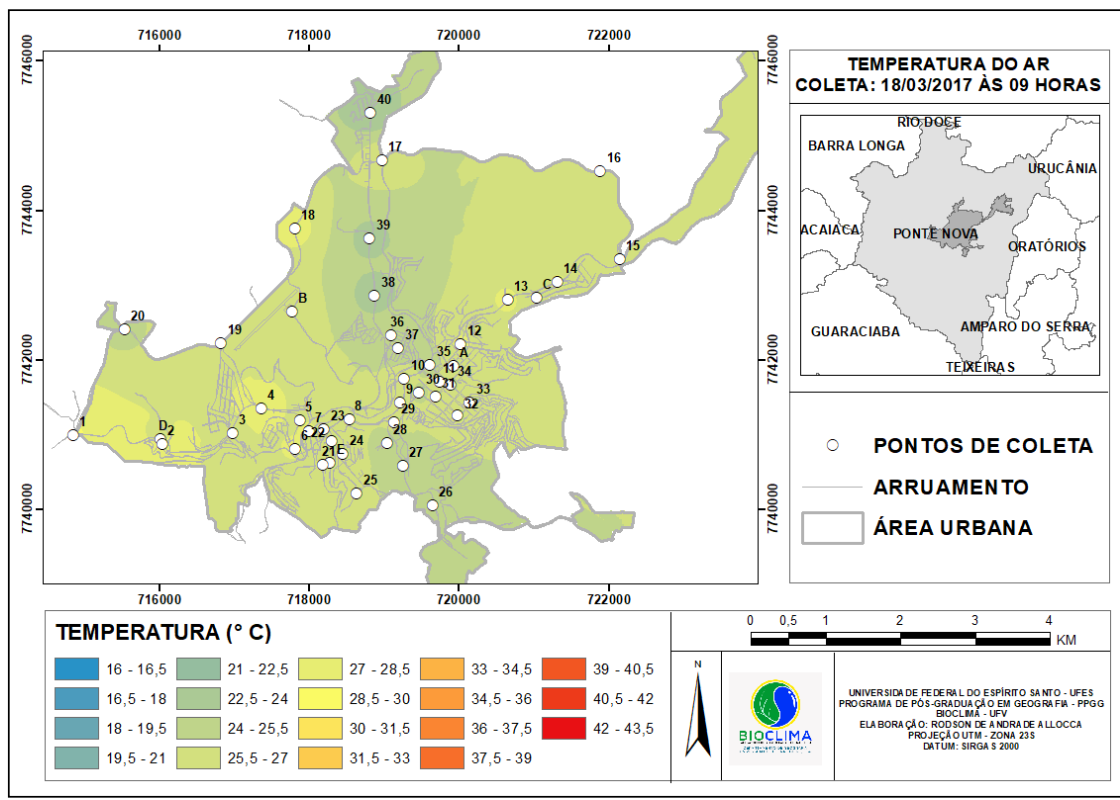

Figura 7 - Campo Térmico (18/03/2017 - às 09h00min). Fonte: elaborado pelo autor.

\begin{tabular}{|c|c|c|c|c|c|c|c|}
\hline \multicolumn{8}{|c|}{ COLETA DE DADOS 18/03/2017 - 09h00min } \\
\hline PONTO DE COLETA & TEMPERATURA $\left({ }^{\circ} \mathrm{C}\right)$ & ALTIMETRIA (M) & RADIAÇÃO GLOBAL (Wh/m²) & TEMPO DE RADIAÇÃO (EM HORAS) & SVF & DENSIDADE DEMOGRÁFICA (Hab/Ha) & ORIENTAÇÃO \\
\hline 27 & 23,80 & 418 & 496586,09 & 5 & 0,537 & 14,00 & relevo plano \\
\hline 28 & 23,60 & 437 & 490697,12 & 10 & 0,766 & 14,00 & nordeste \\
\hline 35 & 23,80 & 421 & 497677,62 & 12 & 0,621 & 68,20 & relevo plano \\
\hline 37 & 23,90 & 446 & 499065,53 & 11 & 0,687 & 227,60 & relevo plano \\
\hline 38 & 23,20 & 417 & 496820,62 & 10 & 0,831 & 6,00 & leste \\
\hline 39 & 23,50 & 414 & 494876,65 & 12 & 0,814 & 6,00 & relevo plano \\
\hline 40 & 22,90 & 410 & 496539,62 & 12 & 0,974 & 11,20 & relevo plano \\
\hline
\end{tabular}

Figura 8 - Tabela de coleta de dados 18/03/2017 - 09h00min. Fonte: elaborado pelo autor.

Após a seleção dos pontos amostrais, foram feitas as análises de correlação linear de Pearson (Figura 9). Entre o SVF e a temperatura do ar foi estabelecida uma fortíssima correlação inversa, ou seja, na medida em que os valores de SVF aumentam, os valores da temperatura do ar diminuem.

\begin{tabular}{|l|c|c|}
\hline \multicolumn{3}{|c|}{ Correlação de Pearson } \\
\hline Fatores & r & Classificação \\
\hline Altimetria & 0,62794 & FORTE \\
\hline Radiação Global & 0,13664 & FRACA \\
\hline Tempo de Radiação & $-0,3223$ & MÉDIA \\
\hline SVF & $-0,8952$ & FORTÍSSIMA \\
\hline Densidade Demográfica & 0,55464 & MÉDIA \\
\hline
\end{tabular}

Figura 9 - Tabela da correlação linear de pearson entre fatores e temperatura do ar. Fonte: elaborada pelo autor. 
O fator SVF tem melhor desempenho na possível explicação dos valores da temperatura, pois o coeficiente de determinação foi de $R^{2}=0,8014$ (Figura 10).

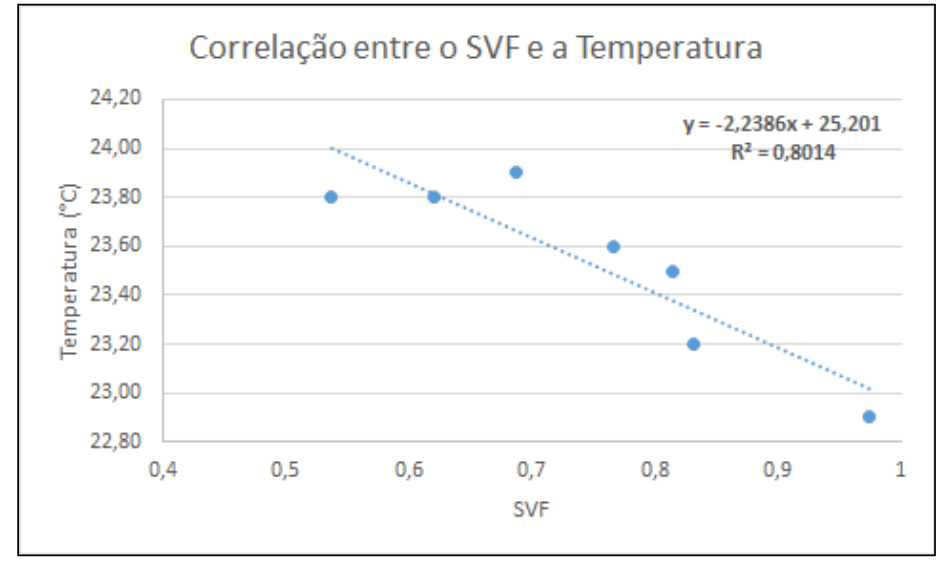

Figura 10 - Correlação entre o SVF e a temperatura do ar. Fonte: elaborado pelo autor.

A maior parte dos pontos com menores valores térmicos apresentaram índices de SVF classificados, de acordo com Collischonn e Ferreira (2015), numa condição de moderada ou baixa obstrução da abóbada celeste, além de, em função da trajetória aparente do sol, estarem expostos à radiação solar direta desde as primeiras horas da manhã.

De acordo com a literatura, esse fato seria favorável a um maior aquecimento, contudo, os valores térmicos não se mostraram elevados. Desse modo, ao considerar os pontos de menores temperatura do ar, pode-se presumir que esse comportamento, mesmo apresentando elevada correlação com SVF, esteja associado a influência do sítio.

A maioria dos pontos que apresentaram menores valores térmicos se encontram em locais onde o relevo predominante é o fundo do vale do Rio Piranga e o vale do Ribeirão Vau-Açú. Nas vertentes dos vales ocorre "a movimentação do ar no sentido descendente e [...] esse movimento do ar é denominado de brisa de montanha ou ventos catabáticos" (FIALHO, 2009; p. 57). O ar frio que escoa pelas encostas é canalizado no fundo dos vales e, possivelmente, a soma do efeito que a forma do relevo desempenha na circulação das brisas locais com a proximidade da calha do rio e seu efeito de arrefecimento pode justificar um retardamento da dinâmica de aquecimento do ar nas primeiras horas da manhã, em relação as demais áreas da cidade.

Resultado semelhante foi encontrado por Martins (1996) ao analisar a temperatura do ar em Juiz de Fora - MG e por Fialho (2009) ao analisar o campo térmico na área central de Viçosa - MG, em coleta realizada no mês de maio, onde pôde verificar temperaturas mais amenas ao longo do vale do rio São Bartolomeu.

Hathway e Sharples (2012) demonstram que o rio é capaz de gerar um efeito de arrefecimento significativo das temperaturas do ar em seu entorno, com maior efetividade durante o período da manhã. 
A maior temperatura do ar observada na coleta realizada durante a manhã foi registrada no Ponto $1\left(28,6^{\circ} \mathrm{C}\right)$, outros pontos apresentaram temperatura do ar num intervalo entre $27,0^{\circ} \mathrm{C}$ e $27,7^{\circ} \mathrm{C}$ e foram selecionados para a análise das áreas mais aquecidas (Figura 11).

As áreas de maior aquecimento se distribuíram na porção oeste da área urbana e também em algumas áreas na porção leste, conforme pôde ser observado na Figura 10. Ao redor dos Pontos 1, 2, 4, 6, 7, 10, 12, 13, 14, 18 e 23 formaram-se núcleos aquecidos.

\begin{tabular}{|c|c|c|c|c|c|c|c|}
\hline \multicolumn{8}{|c|}{ COLETA DE DADOS 18/03/2017 - 09h00min } \\
\hline PONTO DE COLETA & TEMPERATURA $\left({ }^{\circ} \mathrm{C}\right)$ & ALTIMETRIA (M) & RADIAÇÃO GLOBAL (Wh/m²) & TEMPO DE RADIAÇÃO (EM HORAS) & SVF & DENSIDADE DEMOGRÁFICA (Hab/Ha) & ORIENTAÇÃOO \\
\hline 1 & 28,60 & 457 & 500617,50 & 12 & 1 & 0,50 & relevo plano \\
\hline 2 & 27,70 & 501 & 496279,90 & 10 & 0,821 & 0,50 & sudeste \\
\hline 4 & 27,50 & 467 & 484389,65 & 12 & 0,965 & 10,20 & leste \\
\hline 6 & 27,30 & 425 & 495714,90 & 12 & 0,951 & 26,40 & sudeste \\
\hline 7 & 27,20 & 418 & 496870,65 & 10 & 0,815 & 50,50 & relevo plano \\
\hline 10 & 27,10 & 420 & 497204,40 & 12 & 0,864 & 34,00 & relevo plano \\
\hline 12 & 27,40 & 393 & 495996,71 & 8 & 0,466 & 74,30 & oeste \\
\hline 13 & 27,30 & 468 & 495605,25 & 12 & 0,946 & 6,90 & noroeste \\
\hline 14 & 27,10 & 484 & 476906,53 & 12 & 0,776 & 6,90 & noroeste \\
\hline 18 & 27,60 & 499 & 487850,03 & 11 & 0,965 & 6,00 & leste \\
\hline 23 & 27,10 & 446 & 488565,15 & 6 & 0,599 & 50,50 & nordeste \\
\hline
\end{tabular}

Figura 11 - Tabela de coleta de dados 18/03/2017 - 09h00min. Fonte: elaborado pelo autor.

Através das análises de SVF, observou-se que, na maioria dos pontos aquecidos, a trajetória aparente do sol favorece a incidência de radiação solar direta desde as primeiras horas da manhã (Figura 12). As exceções são os pontos 2, 7, 18 e 23 que têm o início de incidência retardado em função de obstruções da abóboda celeste. Ao observar a caracterização dos pontos, foi percebido que em todos eles a intensidade do tráfego de veículos era um aspecto semelhante.

Neste sentido, possivelmente, o calor advindo dos veículos automotores em associação com os demais fatores locais, como os diferentes índices de SVF que contribuem para o aquecimento por dificultar a dispersão da irradiação, pode ter sido um diferencial na geração de maior aquecimento, sobretudo nos pontos de menor incidência da radiação solar no período da manhã, uma vez que todos os pontos onde foram observadas maiores taxas de temperaturas do ar estão em vias importantes de circulação urbana, onde o tráfego, considerando o ritmo típico adaptado das informações obtidas a partir dos dados do Google Maps, varia de moderado a intenso no horário e no dia da observação. 


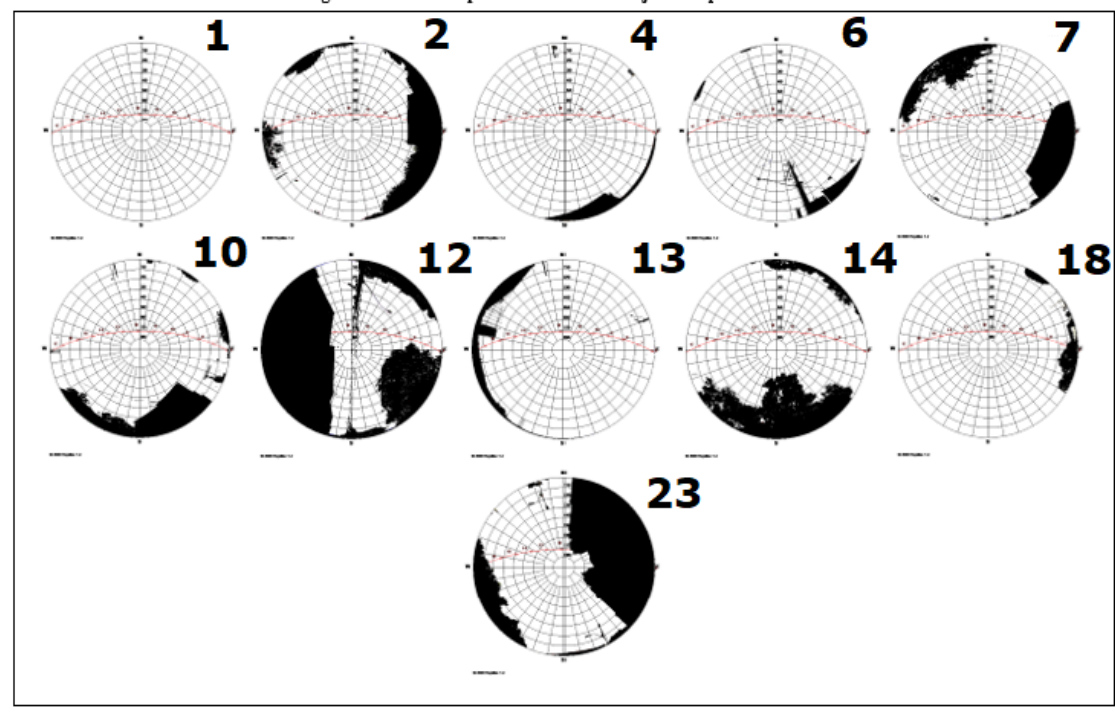

Figura 12 - Gráficos polares contendo a trajetória aparente do sol. Fonte: elaborado pelo autor.

\section{Análise do campo térmico às 15h00min}

O período vespertino revelou a ocorrência de uma variação térmica de $9,0^{\circ} \mathrm{C}$ dentro da área urbana de Ponte Nova. A mínima temperatura do ar registrada foi de $33,9^{\circ} \mathrm{C}$ (Ponto 20) e a máxima de $42,9^{\circ} \mathrm{C}$ no Ponto 9.

A espacialização do campo térmico (Figura 13) demonstrou a ocorrência de áreas com menores temperaturas na porção oeste e nordeste da área urbana.

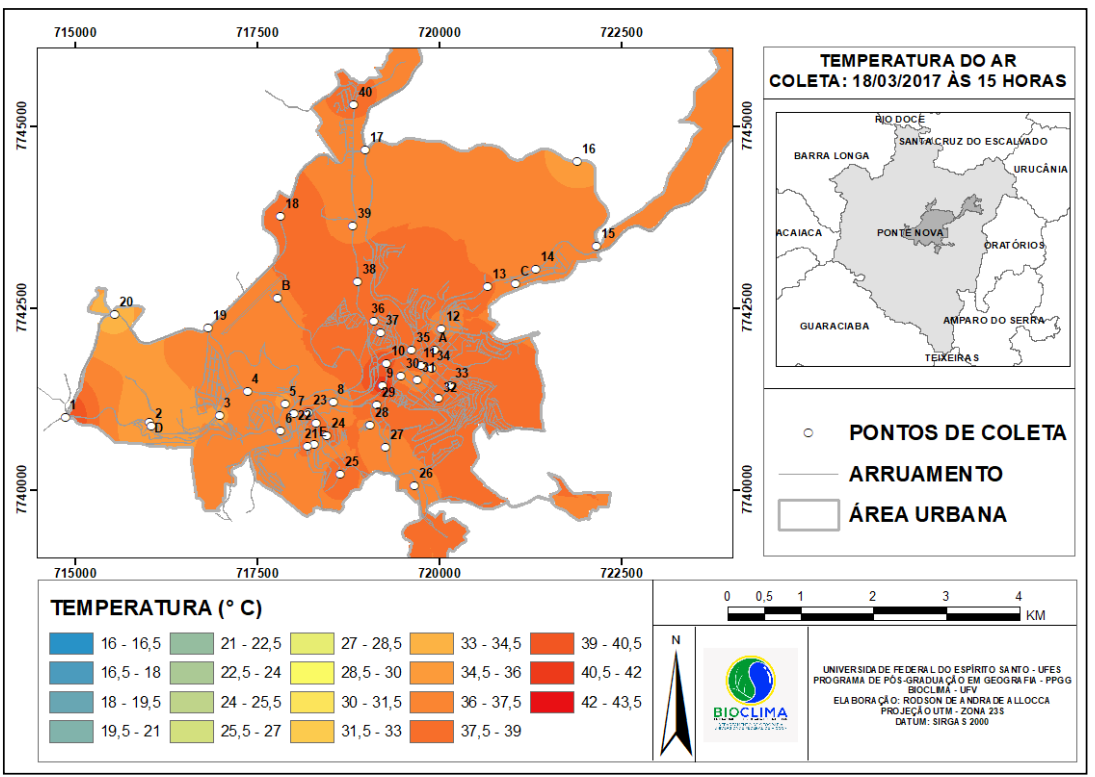

Figura 13 - Campo térmico (18/03/2017 às 15 h00min). Fonte: elaborado pelo autor. 
Os Pontos D, 5, 16, 8 e 3, juntamente com o Ponto 20, foram selecionados para a análise por apresentarem os menores valores de temperatura, variando entre $34,3^{\circ} \mathrm{C}$ e $35,9^{\circ} \mathrm{C}$ (Figura 14).

\begin{tabular}{|c|c|c|c|c|c|c|c|}
\hline \multicolumn{8}{|c|}{$\begin{array}{c}\text { COLETA DE DADOS 18/03/2017 - 15h00min } \\
\end{array}$} \\
\hline PONTO DE COLETA & TEMPERATURA $\left({ }^{\circ} \mathrm{C}\right)$ & ALTIMETRIA (M) & RADIAÇÃO GLOBAL $\left(\mathrm{Wh} / \mathrm{m}^{2}\right)$ & TEMPO DE RADIAÇÃO (EM HORAS) & SVF & DENSIDADE DEMOGRÁFICA (Hab/Ha) & ORIENTAÇ̃̃O \\
\hline D & 34,30 & 4990 & 501179,90 & 10 & 0,86 & 0,50 & leste \\
\hline 5 & 35,20 & 450 & 471232,96 & 9 & 0,773 & 10,20 & sudeste \\
\hline 16 & 35,40 & 536 & 504259,53 & 12 & 0,899 & 1,00 & noroeste \\
\hline 8 & 35,70 & 419 & 495820,40 & 9 & 0,663 & 27,00 & norte \\
\hline 3 & 35,90 & 441 & 495149,56 & 12 & 0,969 & 15,50 & sudeste \\
\hline 20 & 33,90 & 589 & 502820,09 & 12 & 0,964 & 0,50 & oeste \\
\hline
\end{tabular}

Figura 14 - Tabela de coleta de dados 18/03/2017 - 15h00min. Fonte: elaborado pelo autor.

$\mathrm{Na}$ análise de correlação linear de Pearson aplicada aos pontos representativos, os fatores altimetria e densidade demográfica apresentaram classificação forte, os demais fatores apresentaram classificação fraca (Figura 15).

\begin{tabular}{|l|c|c|}
\hline \multicolumn{3}{|c|}{ Correlação de Pearson } \\
\hline Fator & $\mathbf{r}$ & Classificação \\
\hline Altimetria & $-0,74244$ & FORTE \\
\hline Radiação Global & $-0,2725$ & FRACA \\
\hline Tempo de Radiação & $-0,12784$ & FRACA \\
\hline SVF & $-0,32548$ & MÉDIA \\
\hline Densidade Demográfica & 0,71902 & FORTE \\
\hline
\end{tabular}

Figura 15 - Tabela da correlação linear de Pearson entre fatores e temperatura do ar. Fonte: elaborado pelo autor.

O fator altimetria apresentou uma forte correlação inversa com a temperatura do ar. Já a densidade demográfica, apresentou uma correlação forte positiva. Nos pontos de maior densidade os valores térmicos eram relativamente maiores.

Ao analisarmos os gráficos polares (Figura 16) dos pontos de menores valores de temperatura é possível perceber que nos Pontos $D, 5$ e 8 , o início do processo de aquecimento ocorre posteriormente ao início de aquecimento dos demais pontos, fazendo com que, no balanço de energia, a entrada de radiação solar direta seja menor. Esse fator, embora não seja o único a determinar o comportamento térmico, certamente tem grande influência. 


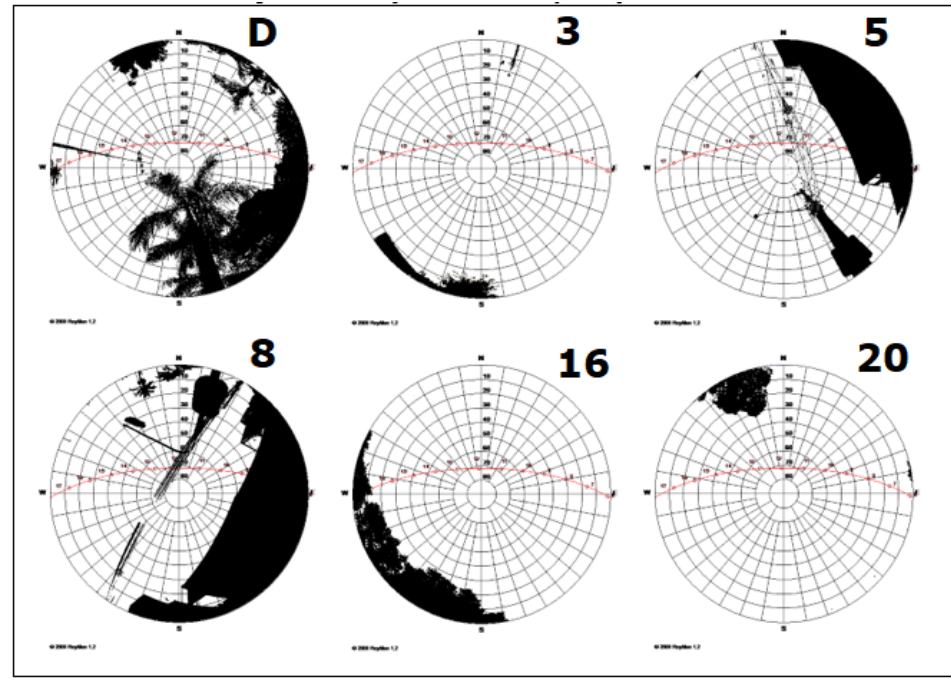

Figura 16 - Gráficos polares contendo a trajetória aparente do sol. Fonte: elaborado pelo autor.

A dinâmica da cidade tem também importância nos valores de temperatura do ar observados e dois aspectos podem ser apontados como relevantes. O primeiro deles é a redução do fluxo de veículos em função do horário e do dia (sábado) em que foi realizada a coleta. O segundo é a própria localização da maior parte dos pontos (excetuando-se o ponto 8), que se encontram afastados das áreas mais centrais da cidade, apresentando baixa densidade demográfica.

O maior valor térmico foi observado no Ponto $9\left(42,9^{\circ} \mathrm{C}\right)$. Destacam-se também os Pontos A, 1, 10, 11, 18, 21, 32, 33, 35, 37 e 38, com temperaturas variando entre $38,1^{\circ} \mathrm{C}$ e $40,4^{\circ} \mathrm{C}$, configurando as áreas de maior aquecimento (Figura 17).

\begin{tabular}{|c|c|c|c|c|c|c|c|}
\hline \multicolumn{8}{|c|}{ COLETA DE DADOS 18/03/2017 - 15h00min } \\
\hline PONTO DE COLETA & TEMPERATURA $\left({ }^{\circ} \mathrm{C}\right)$ & ALTIMETRIA (M) & RADIAÇÃO GLOBAL $\left(\mathrm{Wh} / \mathrm{m}^{2}\right)$ & TEMPO DE RADIAÇÃO (EM HORAS) & SVF & DENSIDADE DEMOGRÁFICA (Hab/Ha) & ORIENTAÇÃO \\
\hline A & 38,70 & 416 & 489047,90 & 11 & 0,701 & 48,80 & oeste \\
\hline 1 & 40,40 & 457 & 500617,50 & 12 & 1 & 0,50 & relevo plano \\
\hline 10 & 40,00 & 420 & 497204,40 & 12 & 0,864 & 34,00 & relevo plano \\
\hline 11 & 38,40 & 424 & 497309,84 & 11 & 0,743 & 35,20 & relevo plano \\
\hline 18 & 38,10 & 499 & 487850,03 & 11 & 0,965 & 6,00 & leste \\
\hline 21 & 38,20 & 474 & 467737,90 & 12 & 0,878 & 24,10 & oeste \\
\hline 32 & 38,20 & 470 & 490193,56 & 8 & 0,714 & 123,40 & norte \\
\hline 33 & 38,30 & 470 & 494613,21 & 12 & 0,854 & 96,70 & noroeste \\
\hline 35 & 38,40 & 421 & 497677,62 & 12 & 0,621 & 68,20 & relevo plano \\
\hline 37 & 38,30 & 446 & 499065,53 & 11 & 0,687 & 227,60 & relevo plano \\
\hline 38 & 38,30 & 417 & 496820,62 & 10 & 0,831 & 6,00 & leste \\
\hline 9 & 42,90 & 420 & 497379,25 & 8 & 0,592 & 34,00 & relevo plano \\
\hline
\end{tabular}

Figura 17 - Tabela de coleta de dados 18/03/2017 - 15h00min. Fonte: elaborado pelo autor.

De acordo com a espacialização do campo térmico na porção central da área urbana ocorre a formação de uma área aquecida que se estende nas direções sudeste, atingindo a vertente onde encontram-se os Pontos 32 e 33, e noroeste até o entorno do Ponto 18. Outra área aquecida, distante da área central da cidade, pode ser observada no entorno do Ponto 1.

Os resultados estatísticos apresentaram fraca e média correlação linear de Pearson entre os fatores climáticos e a temperatura do ar, não sendo possível indicar qual o fator climático possui maior representatividade no comportamento térmico. 
A orientação do relevo foi um fator de grande contribuição na dinâmica de aquecimento dos pontos analisado. Todos os pontos encontram-se em áreas de elevada incidência de radiação solar, distribuindo-se em locais de relevo plano ou em vertentes orientadas para leste, oeste, noroeste e norte, que, de acordo com a literatura, possuem maior exposição à radiação solar do que as orientadas para o sul (DANNI-OLIVEIRA; MENDONÇA, 2007).

\section{Análise do campo térmico às $18 \mathrm{h00min}$}

A coleta de dados realizada no período noturno revelou a ocorrência de uma variação térmica de $6,9^{\circ} \mathrm{C}$ dentro da área urbana de Ponte Nova. A mínima temperatura registrada foi de $28^{\circ} \mathrm{C}$ no Ponto $\mathrm{D}$ e a máxima de $34,9^{\circ} \mathrm{C}$ no Ponto 35.

A espacialização do campo térmico (Figura 18) indicou a ocorrência de áreas com menores temperaturas do ar em diferentes locais da área urbana. $\mathrm{Na}$ porção oeste da cidade destaca-se um núcleo mais pronunciado e outros núcleos estão limitados a certos pontos, podendo ser visualizados nas porções noroeste e leste a partir da área central da cidade. Destacam-se, além do Ponto $D$, os Pontos B, C, E, 2, 3, 4, 5 e 17 como mais representativos, com temperaturas variando entre $29,4^{\circ} \mathrm{C}$ e $30,9^{\circ} \mathrm{C}$ (Figura 19).

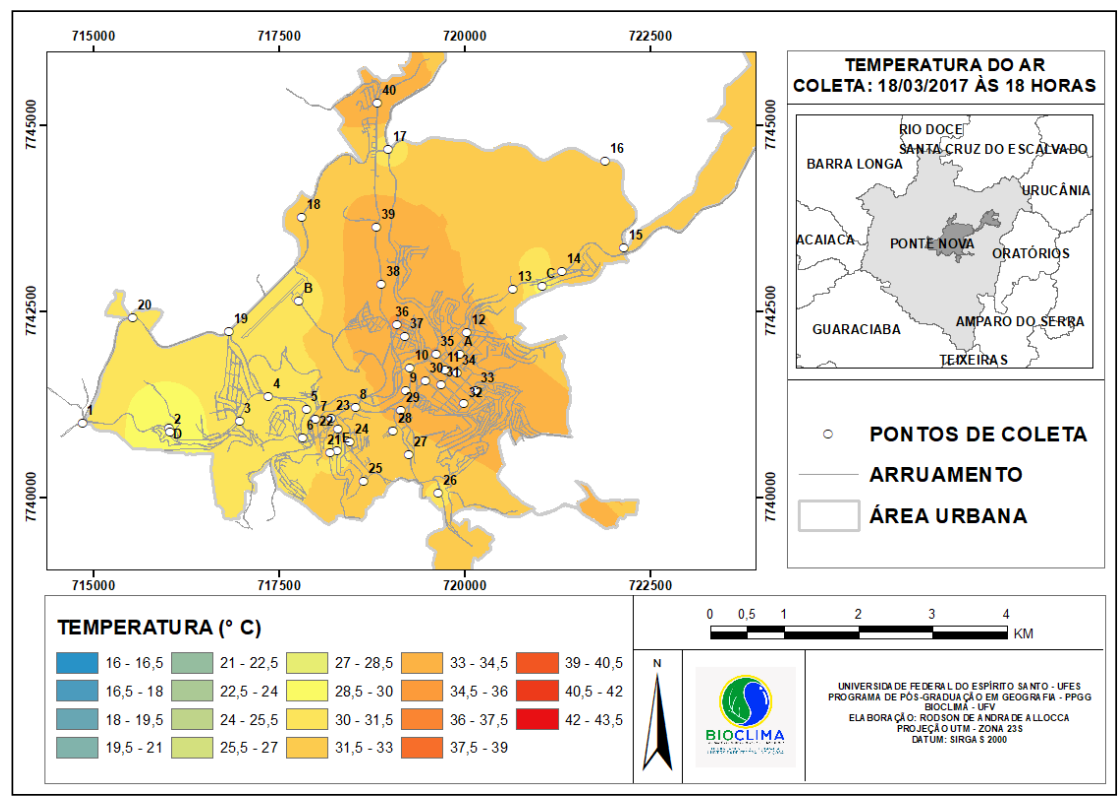

Figura 18 - Campo térmico (18/03/2017 às 18 h00min). Fonte: elaborado pelo autor.

\begin{tabular}{|c|c|c|c|c|c|c|c|}
\hline \multicolumn{8}{|c|}{ COLETA DE DADOS 18/03/2017 - 18h00min } \\
\hline PONTO DE COLETA & TEMPERATURA $\left({ }^{\circ} \mathrm{C}\right)$ & ALTIMETRIA (M) & RADIAÇÃO GLOBAL (Wh/m²) & TEMPO DE RADIAÇÃOO (EM HORAS) & SVF & DENSIDADE DEMOGRÁFICA (Hab/Ha) & ORIENTAÇÃOO \\
\hline $\mathrm{D}$ & 28 & 490 & 501179,90 & 10 & 0,86 & 0,50 & noroeste \\
\hline B & 30,4 & 569 & 507401,75 & 12 & 1 & 4,80 & leste \\
\hline c & 29,4 & 510 & 501578,15 & 12 & 0,781 & 6,90 & sudeste \\
\hline $\mathrm{E}$ & 29,7 & 475 & 491523,18 & 11 & 0,867 & 24,10 & norte \\
\hline 2 & 29,8 & 501 & 496279,90 & 10 & 0,821 & 0,50 & sudeste \\
\hline 3 & 30,5 & 441 & 495149,56 & 12 & 0,969 & 15,50 & relevo plano \\
\hline 4 & 30,7 & 467 & 484389,65 & 12 & 0,965 & 10,20 & leste \\
\hline 5 & 30,4 & 450 & 471232,96 & 9 & 0,773 & 10,20 & norte \\
\hline 17 & 30,9 & 416 & 496744,37 & 12 & 0,969 & 5,60 & leste \\
\hline
\end{tabular}

Figura 19 - Tabela de coleta de dados 18/03/2017 - 18h00min.. Fonte: elaborado pelo autor. 
Dentre os pontos considerados representativos para as menores temperaturas do ar, a partir da espacialização dos mesmos, nota-se que eles se encontram em locais mais afastados da área central da cidade, com baixa densidade demográfica, indicando não haver nessas áreas tanto dinamismo. Os fluxos de pessoas e veículos encontram-se reduzidos. A altimetria é variável, mas de maneira geral os pontos situam-se em áreas mais elevadas, em topos de morros e/ou ao longo de encostas. A análise do SVF indicou que na maioria dos pontos os índices de SVF são elevados, o que favorece a dispersão da energia e a perda de calor para a atmosfera, gerando maior taxa de resfriamento.

No Ponto 35 foi observada a maior temperatura para o horário $\left(34,9^{\circ} \mathrm{C}\right)$. Além do Ponto 35, destacam-se os Pontos 29, 30, 32, 36, 37 e 40, com variação de temperatura entre 34,0 e $37,7^{\circ} \mathrm{C}$ (Figura 20).

\begin{tabular}{|c|c|c|c|c|c|c|c|}
\hline \multicolumn{8}{|c|}{ COLETA DE DADOS 18/03/2017 - 18h00min } \\
\hline PONTO DE COLETA & TEMPERATURA $\left({ }^{\circ} \mathrm{C}\right)$ & ALTIMETRIA (M) & RADIAÇÃO GLOBAL (Wh/m²) & TEMPO DE RADIAÇÃO (EM HORAS) & SVF & DENSIDADE DEMOGRÁFICA ( $\mathrm{Hab} / \mathrm{Ha}$ ) & ORIENTAÇÃO \\
\hline 29 & 34,6 & 417 & 496960,21 & 10 & 0,701 & 76,40 & leste \\
\hline 30 & 34 & 440 & 497110,06 & 11 & 0,671 & 80,30 & oeste \\
\hline 32 & 34 & 470 & 490193,56 & 8 & 0,714 & 123,40 & noroeste \\
\hline 35 & 34,9 & 421 & 497677,62 & 12 & 0,621 & 68,20 & relevo plano \\
\hline 36 & 34,7 & 417 & 497157,28 & 11 & 0,779 & 6,00 & relevo plano \\
\hline 37 & 34,5 & 446 & 499065,53 & 11 & 0,687 & 227,60 & oeste \\
\hline 40 & 34,5 & 410 & 496539,62 & 12 & 0,974 & 11,20 & relevo plano \\
\hline
\end{tabular}

Figura 20 - Tabela de coleta de dados 18/03/2017 - 18h00min. Fonte: elaborado pelo autor.

A espacialização do campo térmico, conforme pôde ser observado anteriormente (Figura 18), indicou a ocorrência de um núcleo de maior aquecimento na porção central da área urbana, alongando-se na direção norte, assim como um núcleo no entorno do Ponto 29 e outro na porção mais ao norte da área urbana, no entorno do Ponto 40.

Uma característica comum à maioria dos Pontos 29, 35, 36 e 40 é o fato de estarem situados em porções mais baixas do relevo, no fundo de vale, em áreas onde o mapeamento de orientação das vertentes apontou como sendo de relevo plano, a única exceção o Ponto 29 que possui orientação leste e está numa porção do relevo com baixa declividade de 1,9\%. Os Pontos 30, 32 e 37 situam-se em cotas mais elevadas na porção intermediária da encosta de orientação (Pontos 30 e 37 - oeste; Ponto 32 - noroeste) favorável à incidência da radiação solar até o momento do pôr do sol.

Os Pontos 29, 30, 32, 35 e 37, além de estarem numa topografia favorável ao aquecimento, estão localizados em áreas de adensamento urbano elevado e altas taxas de densidade demográfica. Com exceção dos Pontos 29 e 32 , os pontos recebem grande quantidade de radiação solar direta, favorecendo o aquecimento diurno. Além disso, com exceção do Ponto 40, os pontos apresentam um certo grau de obstrução da abóboda celeste, fator que dificulta a dissipação da energia térmica para a atmosfera gerando assim núcleos de maior aquecimento.

\subsection{EPISÓDIO DE INVERNO (27/07/2017)}

\section{Síntese da condição sinótica}

Nos dois dias que antecederam o episódio de coleta de dados predominou na região a Massa Tropical Continental (mTc). No dia 25/07 esse sistema atmosférico estava com atuando com bastante força, fazendo com que 
as temperaturas do ar ficassem elevadas. Já no dia 26/07 a mTc perdeu força com a aproximação da $\mathrm{mPa}$. No dia 27/07 a mPa se aproximou da região, causando queda nas temperaturas do ar e diminuição da umidade relativa do ar.

\section{Análise do campo térmico às 09h00min}

A coleta de dados realizada no período matutino, às $09 \mathrm{~h} 00 \mathrm{~min}$, revelou a ocorrência de uma variação térmica de $13,8^{\circ} \mathrm{C}$ dentro da área urbana de Ponte Nova. A mínima temperatura registrada foi de $16,2^{\circ} \mathrm{C}$ no Ponto 40 e a máxima de $30^{\circ} \mathrm{C}$ no Ponto 37.

Os Pontos A, B, 2, 38 e 39, juntamente com o Ponto 40, representam as menores taxas de temperatura registradas. As temperaturas nesses pontos variaram entre $16,5^{\circ} \mathrm{C}$ e $19,8^{\circ} \mathrm{C}$ (Figura 21 ).

\begin{tabular}{|c|c|c|c|c|c|c|c|}
\hline \multicolumn{8}{|c|}{ COLETA DE DADOS 27/07/2017 - 09h00min } \\
\hline PONTO DE COLETA & TEMPERATURA $\left({ }^{\circ} \mathrm{C}\right)$ & ALTIMETRIA (M) & RADIAÇÃO GLOBAL (Wh/m²) & TEMPO DE RADIAÇÃO (EM HORAS) & SVF & DENSIDADE DEMOGRÁFICA ( $\mathrm{Hab} / \mathrm{Ha})$ & ORIENTAÇÃO \\
\hline A & 19 & 416 & 332540,34 & 5 & 0,70 & 48,80 & oeste \\
\hline$B$ & 19,5 & 569 & 341100,31 & 11 & 1,00 & 4,80 & relevo plano \\
\hline 2 & 19,8 & 501 & 323237,96 & 9 & 0,82 & 0,50 & sudeste \\
\hline 38 & 17,4 & 417 & 334403,93 & 10 & 0,83 & 6,00 & leste \\
\hline 39 & 16,5 & 414 & 331403,75 & 10 & 0,81 & 6,00 & relevo plano \\
\hline 40 & 16,2 & 410 & 332307,68 & 11 & 0,97 & 11,20 & relevo plano \\
\hline
\end{tabular}

Figura 21 - Tabela de coleta de dados 27/07/2017 - 09h00min. Fonte: elaborado pelo autor.

A espacialização do campo térmico (Figura 22) indica a ocorrência de áreas de menores temperaturas na direção norte, o entorno dos Pontos 38, 39 e 40, a noroeste, no Ponto B, a oeste, do Ponto 2 e no entorno do Ponto $A$, situado na área central da mancha urbana.

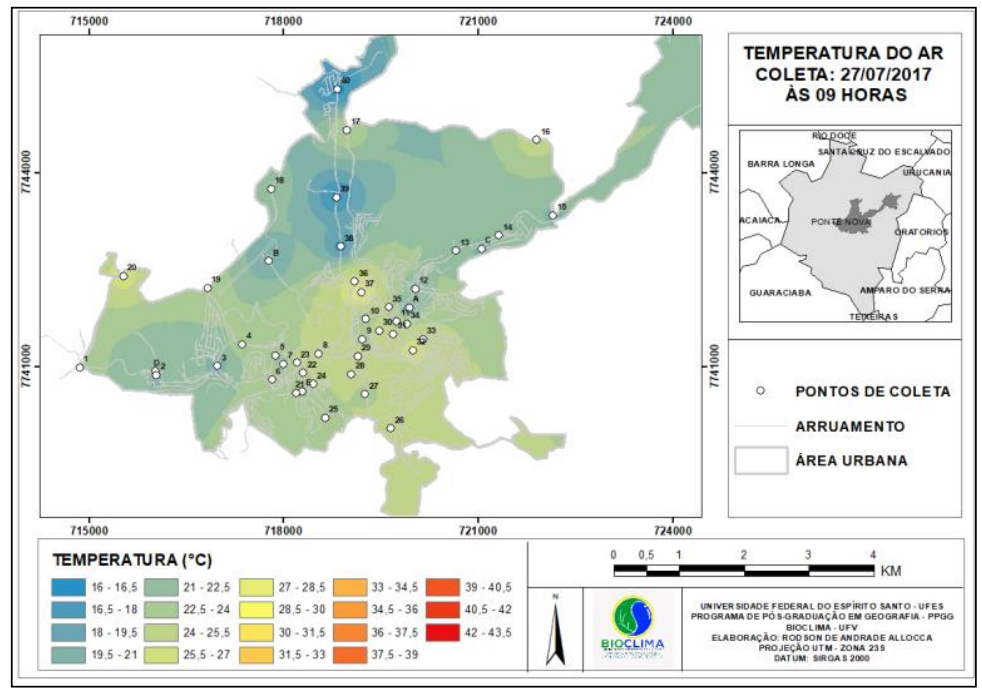

Figura 22 - Campo térmico (27/07/2017 às 09h00min). Fonte: elaborado pelo autor.

A altimetria apresentou a maior correlação linear dentre os fatores climáticos e a temperatura do ar, uma correlação forte positiva (Figura 23). Os Pontos 38, 39 e 40, assim como ocorreu no episódio de verão, destacaram-se, para o horário das 09h00min, como pontos de menores valores térmicos. A localização desses pontos está associada ao fundo do vale do Rio Piranga e as menores temperaturas ocorreram no trecho do vale onde se observa menor adensamento urbano. Nas porções do vale associadas a um maior adensamento 
de construções, não foram observados os mesmos valores de temperatura do ar. Neste sentido, mesmo o rio atuando como um elemento regulador da temperatura do ar, quando associado a maiores taxas de adensamento de construções, sua capacidade de arrefecimento do ar nas primeiras horas da manhã fica parcialmente comprometida.

\begin{tabular}{|l|c|c|}
\hline \multicolumn{3}{|c|}{ Correlação de Pearson } \\
\hline Fator & $\mathbf{r}$ & Classificação \\
\hline Altimetria & 0,734336 & FORTE \\
\hline Radiação Global & $-0,06402$ & FRACA \\
\hline Tempo de Radiação & $-0,3869$ & MÉDIA \\
\hline SVF & $-0,15731$ & FRACA \\
\hline Densidade Demográfica & 0,135005 & FRACA \\
\hline
\end{tabular}

Figura 23 - Tabela da correlação linear de Pearson entre fatores e temperatura do ar. Fonte: elaborado pelo autor.

Os pontos 38, 39 e 40 localizam-se nas proximidades da calha do rio e neles, notadamente, os valores térmicos apresentam-se influenciados pela circulação noturna da brisa da montanha que é potencializada pelo efeito térmico do corpo hídrico e pela baixa taxa de adensamento urbano, mantendo temperaturas mais baixas nas primeiras horas da manhã.

O mesmo efeito não pôde ser observado no Ponto $A$, que também se situa em baixa cota altimétrica, porém em local afastado do leito do rio. Nesse ponto, com maior adensamento urbano em comparação aos pontos anteriormente citados, a temperatura do ar é relativamente mais elevada.

A maior temperatura do ar foi registrada no Ponto $37\left(30,0^{\circ} \mathrm{C}\right)$ e os Pontos 8, 20, 23, 26, 28, 31, 32, 33 e 36 (Figura 24) foram representativos, pois, juntamente com o Ponto 37 , apresentaram os maiores valores térmicos, com temperaturas entre $25,1^{\circ} \mathrm{C}$ e $26,9^{\circ} \mathrm{C}$, conforme apresentado.

\begin{tabular}{|c|c|c|c|c|c|c|c|}
\hline \multicolumn{8}{|c|}{ COLETA DE DADOS 27/07/2017 - 09h00min } \\
\hline PONTO DE COLETA & TEMPERATURA $\left({ }^{\circ} \mathrm{C}\right)$ & ALTIMETRIA (M) & RADIAÇÃO GLOBAL $\left(\mathrm{Wh} / \mathrm{m}^{2}\right)$ & TEMPO DE RADIAÇÃ̃o (EM HORAS) & SVF & DENSIDADE DEMOGRÁFICA (Hab/Ha) & ORIENTAÇÃO \\
\hline 8 & 25,6 & 419 & 337197,71 & 9 & 0,66 & 27,00 & norte \\
\hline 20 & 25,9 & 589 & 336839,31 & 11 & 0,96 & 0,50 & oeste \\
\hline 23 & 25,1 & 446 & 358778,03 & 5 & 0,60 & 50,50 & nordeste \\
\hline 26 & 25,1 & 430 & 338404,53 & 10 & 0,98 & 0,40 & leste \\
\hline 28 & 25,4 & 437 & 347710,21 & 7 & 0,77 & 14,00 & nordeste \\
\hline 31 & 25,9 & 423 & 355919,81 & 8 & 0,56 & 80,30 & norte \\
\hline 32 & 26,9 & 470 & 366620,56 & 9 & 0,71 & 123,40 & norte \\
\hline 33 & 25,6 & 470 & 351971,50 & 11 & 0,85 & 96,70 & noroeste \\
\hline 36 & 25,6 & 417 & 335319,53 & 11 & 0,78 & 6,00 & noroeste \\
\hline 37 & 30 & 446 & 334479,06 & 10 & 0,69 & 227,60 & relevo plano \\
\hline
\end{tabular}

Figura 24 - Tabela de coleta de dados 27/07/2017 - 09h00min. Fonte: elaborado pelo autor.

Na espacialização do campo térmico, nota-se que a área aquecida de maior expressividade está disposta no cento da mancha urbana, descontinuada pela presença da calha do rio em certos pontos, mas ocupando grande parte da área de maior adensamento de construções. Os Pontos 20 e 26 estão localizados em áreas de menor densidade demográfica, porém favorecidos pela orientação oeste e leste, respectivamente. Apresentam valores térmicos elevados e situamse às margens de rodovias importantes de acesso à cidade, onde o tráfego fazse elemento constante e a cobertura asfáltica somada ao calor advindo dos veículos automotores eleva os valores térmicos.

Na análise do coeficiente de correlação linear de Pearson (Figura 25), pode ser verificado que a densidade demográfica é o fator climático que apresenta melhor resultado no comportamento térmico observado. 


\begin{tabular}{|l|c|c|}
\hline \multicolumn{3}{|c|}{ Correlação de Pearson } \\
\hline Fator & $\mathbf{r}$ & Classificação \\
\hline Altimetria & 0,048846 & FRACA \\
\hline Radiação Global & $-0,18698$ & FRACA \\
\hline Tempo de Radiação & 0,235453 & FRACA \\
\hline SVF & $-0,21174$ & FRACA \\
\hline Densidade Demográfica & 0,882314 & FORTE \\
\hline
\end{tabular}

Figura 25 - Tabela da correlação linear de Pearson entre fatores e temperatura do ar. Fonte: elaborado pelo autor.

Os Pontos 31, 32 e 37 apresentaram as maiores temperaturas do ar dentre os pontos aquecidos e a relação entre densidade demográfica e temperatura é evidenciada, pois esses pontos se encontram em meio a elevados valores de densidade. Além do fator densidade, no caso desses pontos, a orientação norte (Pontos 31 e 32) e o relevo mais aplainado (Ponto 37) contribuem para a elevação da temperatura do ar, uma vez que expõem o local a maiores taxas de radiação solar direta.

Existe uma grande diversidade da geometria urbana nos pontos observados. Nos Pontos 8, 23, 31, 32 e 37 o início da incidência de radiação solar direta é afetado pelas obstruções da abóbada celeste. Embora o início da radiação seja retardado, a obstrução gera também um efeito de maior armazenamento da energia térmica, uma vez que a irradiação é, parcialmente, comprometida pela às estruturas físicas do entorno.

Nos Pontos 28 e 36 a radiação solar incide desde as primeiras horas da manhã e as obstruções da abóboda celeste dificultam o processo de irradiação, gerando condições para a elevação da temperatura do ar. Nos Pontos 20, 26 e 33 o SVF é elevado, ou seja, a radiação solar incidente não é influenciada por obstruções.

\section{Análise do campo térmico às 15h00min}

A coleta de dados realizada no período vespertino às $15 \mathrm{~h} 00 \mathrm{~min}$ revelou a ocorrência de uma variação térmica de $9,2^{\circ} \mathrm{C}$ dentro da área urbana de Ponte Nova. A mínima temperatura do ar registrada foi de $21,2^{\circ} \mathrm{C}$ no Ponto 40 e a máxima de $30,4^{\circ} \mathrm{C}$ no Ponto 33 .

Os Pontos 38 e 39, juntamente com o Ponto 40, representam as menores taxas de temperatura registradas (Figura 26). As temperaturas nestes pontos foram de $22,2^{\circ} \mathrm{C}$ e $22,6^{\circ} \mathrm{C}$, respectivamente.

\begin{tabular}{|c|c|c|c|c|c|c|c|}
\hline \multicolumn{8}{|c|}{ COLETA DE DADOS 27/07/2017 - 15h00min } \\
\hline PONTO DE COLETA & TEMPERATURA $\left({ }^{\circ} \mathrm{C}\right)$ & ALTIMETRIA (M) & RADIAÇÃO GLOBAL (Wh/m²) & TEMPO DE RADIAÇÃO (EM HORAS) & SVF & DENSIDADE DEMOGRÁFICA (Hab/Ha) & ORIENTAÇÃO \\
\hline 38 & 22,6 & 417 & 334403,93 & 10 & 0,83 & 6,00 & leste \\
\hline 39 & 22,2 & 414 & 331403,75 & 10 & 0,81 & 6,00 & relevo plano \\
\hline 40 & 21.2 & 410 & 332307,68 & 11 & 0,97 & 11,20 & relevo plano \\
\hline
\end{tabular}

Figura 26 - Tabela de coleta de dados 27/07/2017 - 15h00min. Fonte: elaborado pelo autor.

A partir da espacialização do campo térmico (Figura 27), nota-se a formação de núcleos de menores temperaturas do ar, bastante circunscritos, no entorno dos Pontos 38, 39 e 40, ao norte da área urbana. 


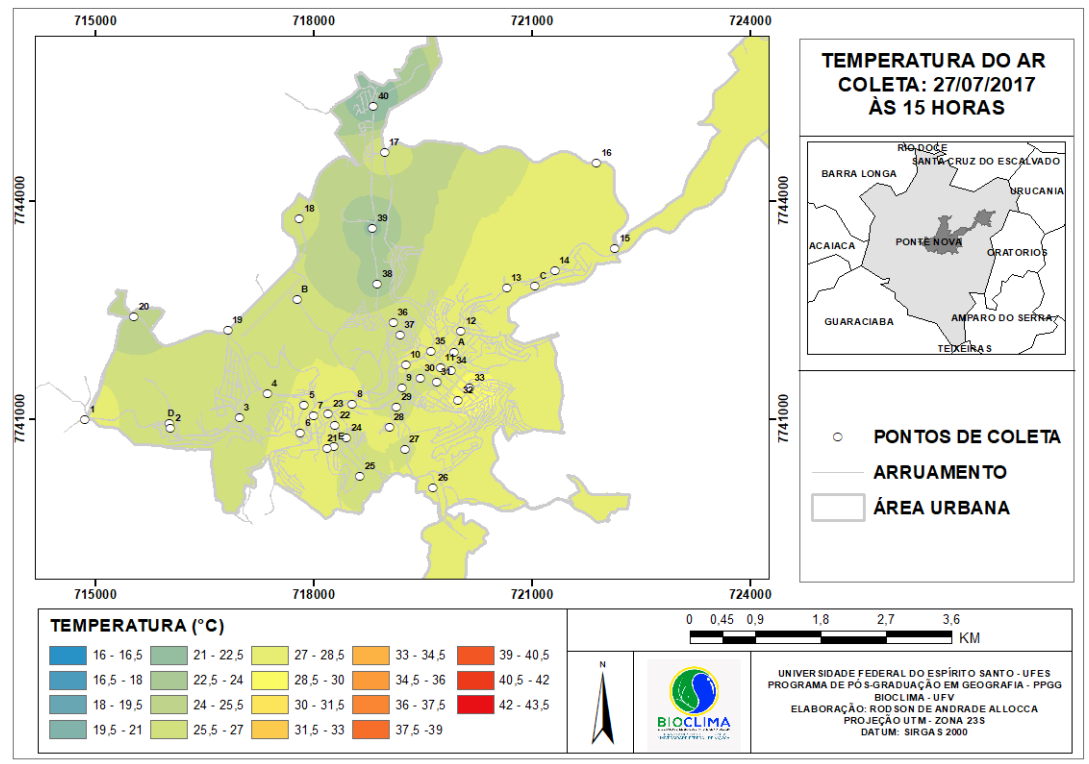

Figura 27 - Campo térmico (27/07/2017 às 15h00min). Fonte: elaborado pelo autor.

Estes pontos (38, 39 e 40) localizam-se no fundo do vale do Rio Piranga. Tal fator pode ser entendido como importante influência nos índices térmicos, considerando que o rio atua como um regulador da temperatura do ar, uma vez que seu processo de aquecimento é mais lento e, com isso, é capaz de gerar efeito de arrefecimento da atmosfera em seu entorno. Embora o rio exerça esse papel, é importante notar que o comportamento da temperatura observada nos pontos em questão não é percebido ao longo de todo curso do rio através da área urbana. Nos trechos onde o rio passa por localidades mais adensadas de construções, aparentemente, o potencial de arrefecimento sofre uma redução e, nesse sentido, as temperaturas apresentaram-se mais elevadas (HATHWAY; SHARPLES, 2012).

A maior temperatura do ar foi registrada no Ponto $33\left(30,4^{\circ} \mathrm{C}\right)$ e os Pontos $\mathrm{C}, 1,7,13,14,21,32$ e 35 foram representativos, pois, juntamente com o Ponto 37, apresentaram os maiores valores térmicos, com temperaturas entre $28,0^{\circ} \mathrm{C}$ e $29,8^{\circ} \mathrm{C}$ (Figura 28 ).

\begin{tabular}{|c|c|c|c|c|c|c|c|}
\hline \multicolumn{8}{|c|}{ COLETA DE DADOS 27/07/2017 - 15h00min } \\
\hline PONTO DE COLETA & TEMPERATURA $\left({ }^{\circ} \mathrm{C}\right)$ & ALTIMETRIA (M) & RADIAÇÃO GLOBAL (Wh/m²) & TEMPO DE RADIAÇÃO (EM HORAS) & SVF & DENSIDADE DEMOGRÁFICA (Hab/Ha) & ORIENTAÇÃOO \\
\hline $\mathrm{c}$ & 28,2 & 510 & 377490,81 & 11 & 0,78 & 6,90 & nordeste \\
\hline 1 & 28,6 & 457 & 335624,28 & 11 & 0,95 & 0,50 & relevo plano \\
\hline 7 & 29,8 & 418 & 332644,68 & 10 & 0,82 & 50,50 & relevo plano \\
\hline 13 & 28,5 & 468 & 341015,56 & 11 & 0,95 & 6,90 & noroeste \\
\hline 14 & 28 & 484 & 377490,81 & 11 & 0,78 & 6,90 & noroeste \\
\hline 21 & 28,1 & 474 & 339566,43 & 11 & 0,88 & 24,10 & oeste \\
\hline 32 & 29,2 & 470 & 366620,56 & 9 & 0,71 & 123,40 & norte \\
\hline 33 & 30,4 & 470 & 351971,50 & 11 & 0,85 & 96,70 & noroeste \\
\hline 35 & 28,2 & 421 & 333396,84 & 10 & 0,62 & 68,20 & relevo plano \\
\hline
\end{tabular}

Figura 28 - Tabela de coleta de dados 27/07/2017 - 15h00min. Fonte: elaborado pelo autor.

Na espacialização do campo térmico, nota-se que a área aquecida apresenta múltiplos núcleos. Há ocorrências nas porções: sudeste, no entorno dos Pontos 32 e 33; leste, no entorno dos Pontos 13, 14 e C; na porção central, no entorno do Ponto 35; oeste, no entorno do Ponto 1; e em outro setor da área central, no entorno dos Pontos 7 e 21. 
Os Pontos C, 13 e 14, apresentam relevo com orientação noroeste, favorecendo a incidência de radiação solar direta. Nos Pontos 13 e 14, além da orientação favorável ao processo de aquecimento, podemos somar o efeito do intenso tráfego de veículos no local onde estão situados (Rodovia MG-329) em que a cobertura asfáltica, com baixo albedo, aumenta a temperatura do ar. 0 Ponto 1 , que se situa em relevo plano, recebendo altas taxas de radiação solar direta, também apresenta intenso tráfego de veículos que, em função do calor gerado pelos motores dos automóveis, recebe um acréscimo de energia térmica levando a uma elevação da temperatura do ar. No Ponto 21 , a orientação voltada para oeste e a densidade demográfica contribuem para a elevada temperatura do ar observada no local.

O Ponto 35 tem seu comportamento térmico justificado por apresentar um moderado grau de obstrução da abóbada celeste ( $S V F=0,62$ ), que contribui para a retenção do calor por dificultar a dispersão da radiação, está em relevo plano favorecendo a incidência da radiação solar direta, em área de uso comercial onde predominam fluxos de veículos e pessoas bastante intensos, onde há elevada densidade demográfica e maior adensamento de construções.

No Ponto 7 podemos destacar, como características que contribuem para o registro de elevado índice térmico, o relevo plano que favorece a incidência da radiação solar e uma alta densidade demográfica.

Nos Pontos 32 e 33 o relevo de orientação noroeste e norte, respectivamente, associado às altas taxas de densidade demográfica condicionam a ocorrência de elevadas temperaturas do ar nesses locais.

Apesar de variados valores de SVF, em todos os pontos, a trajetória aparente do sol favorece a incidência de radiação solar direta e, nos casos em que há obstrução da abóbada celeste, o efeito da geometria urbana no entorno do ponto acaba favorecendo para maior retenção da energia, pois no processo de irradiação a dispersão da energia térmica é dificultada.

\section{Análise do campo térmico às 18h00min}

A coleta de dados realizada no período noturno, às $18 \mathrm{~h} 00 \mathrm{~min}$, revelou a ocorrência de uma variação térmica de $5,0^{\circ} \mathrm{C}$ dentro da área urbana de Ponte Nova. A mínima temperatura do ar registrada foi de $19,9^{\circ} \mathrm{C}$ no Ponto $\mathrm{D}$ e a máxima de $24,9^{\circ} \mathrm{C}$ no Ponto 35 .

Os Pontos 26, 27, 28, 39 e 40, juntamente com o Ponto D, representam as menores taxas de temperatura do ar registradas (Figura 29). As temperaturas do ar nesses pontos variaram entre $21,0^{\circ} \mathrm{C}$ e $21,7^{\circ} \mathrm{C}$.

\begin{tabular}{|c|c|c|c|c|c|c|c|}
\hline \multicolumn{8}{|c|}{ COLETA DE DADOS 27/07/2017 - 18h00min } \\
\hline PONTO DE COLETA & TEMPERATURA $\left({ }^{\circ} \mathrm{C}\right)$ & ALTIMETRIA (M) & RADIAÇÃO GLOBAL (Wh/m²) & TEMPO DE RADIAÇÃO (EM HORAS) & SVF & DENSIDADE DEMOGRÁFICA ( $\mathrm{Hab} / \mathrm{Ha}$ ) & ORIENTAÇÃO \\
\hline $\mathrm{D}$ & 19,9 & 490 & 334418,21 & 10 & 0,66 & 0,50 & leste \\
\hline 26 & 21 & 430 & 338404,53 & 10 & 0,98 & 0,40 & leste \\
\hline 27 & 21,4 & 418 & 332400,84 & 1 & 0,54 & 14,00 & relevo plano \\
\hline 28 & 21,6 & 437 & 347710,21 & 7 & 0,77 & 14,00 & nordeste \\
\hline 39 & 21,2 & 414 & 331403,75 & 10 & 0,81 & 6,00 & relevo plano \\
\hline 40 & 21,7 & 410 & 332307,68 & 11 & 0,97 & 11,20 & relevo plano \\
\hline
\end{tabular}

Figura 29 - Tabela de coleta de dados 27/07/2017 - 18h00min. Fonte: elaborado pelo autor.

A espacialização do campo térmico (Figura 30) apontou a ocorrência de núcleos de menores temperaturas nas porções sul, norte e oeste da área urbana. Os pontos localizados no fundo do vale do Rio Piranga (Pontos 39 e 40) 
e também do Ribeirão Vau-Açu (Pontos 26, 27 e 28), possivelmente, assim como em episódios anteriores, foram influenciados pela circulação da brisa de montanha, que após o pôr do sol passa a atuar levando o ar frio do topo das encostas para as porções mais baixas do relevo (FIALHO, 2009).

O Ponto D, por sua vez, localizado próximo à lagoa do Clube AABB, rodeado por um vale de menor proporção comparado ao vale do Rio Piranga, apresentou a menor temperatura para o horário. Nesse sentido, é provável que o ponto também esteja sobre a atuação da brisa da montanha. Associada a essa condição dinâmica, podemos destacar a baixa densidade demográfica e menor padrão de adensamento de construções.

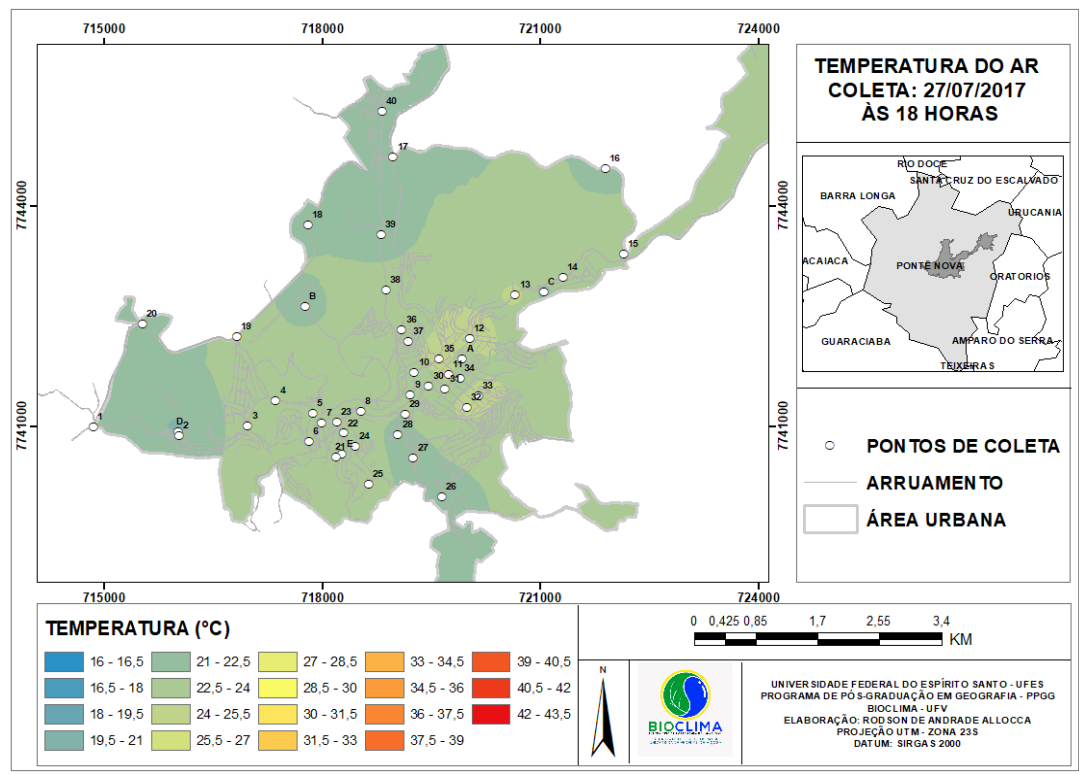

Figura 30 - Campo térmico (27/07/2017 às 18h00min). Fonte: elaborado pelo autor.

Não há interferência do SVF na dinâmica de entrada de radiação solar direta nos Pontos 39 e 40 . O processo de entrada e saída da energia é facilitado pela ausência de obstáculos. Nos Pontos 27 e 28, em função da trajetória solar observada para a época do ano e das obstruções da abóbada celeste, a incidência de radiação solar direta é menor, sendo que no Ponto 27 o tempo de radiação solar direta não ultrapassa o intervalo uma hora ao longo de todo o dia (Figura 31). 


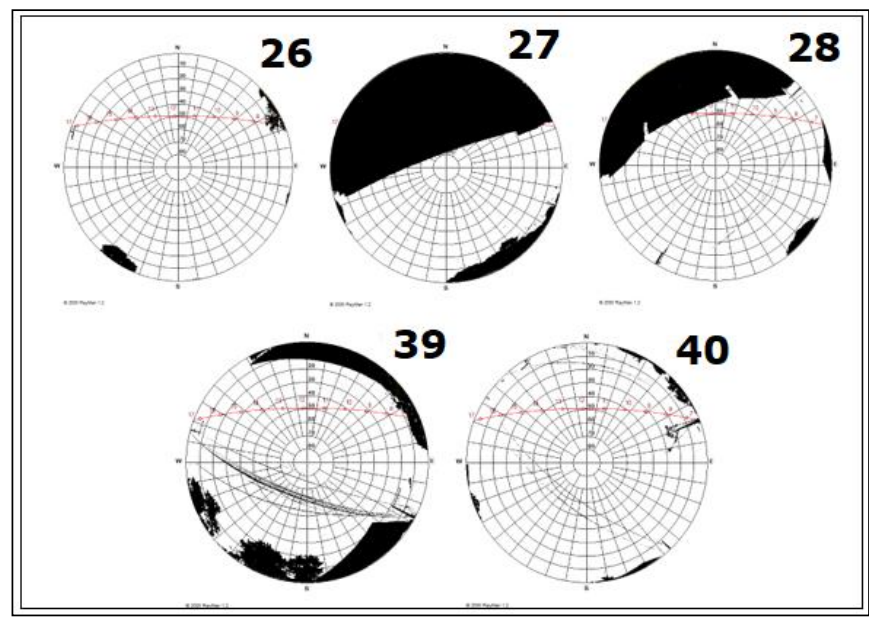

Figura 31 - Gráficos polares contendo a trajetória aparente do sol. Fonte: elaborado pelo autor.

A maior temperatura do ar foi registrada no Ponto $35\left(24,9^{\circ} \mathrm{C}\right)$. A espacialização do campo térmico, conforme pôde ser observada na Figura 32, demonstrou a formação de uma grande área aquecida sobre quase a totalidade da área urbana. A maior parte dos pontos amostrais está inserida nessa área de maior aquecimento.

No dia da coleta, de acordo com a análise sinótica, houve a aproximação da $\mathrm{mPa}$, que gerou uma certa homogeneização das temperaturas, sobretudo para o período noturno, dificultando a percepção da atuação de fatores locais no comportamento térmico.

\section{CONSIDERAÇÕES FINAIS}

Na análise do campo térmico da área urbana de Ponte Nova-MG, os resultados demonstraram a ocorrência de diferenças térmicas intraurbanas nos episódios sazonais de coleta, mesmo sob a atuação de diferentes sistemas atmosféricos. A maior diferença térmica $\left(13,8^{\circ} \mathrm{C}\right)$ foi observada no inverno, na coleta realizada em 27 de julho de 2017, no horário das 09h00min, quando atuava a mPa, garantindo maior estabilidade atmosférica e, nesse sentido, possibilitando maior atuação dos fatores locais na configuração do campo térmico. Resultado semelhante foi encontrado por Martins (1996) em seu estudo sobre a influência do sítio e da estrutura urbana na temperatura do ar em Juiz de Fora - MG. Em seu estudo, o autor relata uma diferença de $12,8{ }^{\circ} \mathrm{C}$ de temperatura do ar, em episódio sazonal de inverno.

O uso da técnica de transects móveis mostrou-se viável para o levantamento dos dados de temperatura do ar e a equação de correção de dados foi fundamental para a utilização da técnica na área estudada, em função das dimensões e da logística de desenvolvimento das coletas.

A variedade dos fatores climáticos observados no escopo da pesquisa tornou a análise uma tarefa complexa. A partir das informações geradas pelas coletas de dados, não foi possível determinar as causas exatas que justificam as diferenças encontradas no campo térmico e afirmar a ocorrência do fenômeno de ilha de calor atmosférica poderia ser um equívoco. Desse modo, podemos considerar que a estrutura urbana ainda é incapaz de gerar um clima urbano e o 
clima local é condicionado em maior proporção pelas características do sítio onde a cidade se desenvolve.

Espera-se que a continuidade desta pesquisa possa trazer novos elementos que melhor possam delinear o papel de cada fator na geração do comportamento térmico na área urbana de Ponte Nova. Desse modo, fica indicada a demanda por maior aprofundamento da temática e também por novos desdobramentos desta pesquisa.

\section{BIBLIOGRAFIA}

AB'SÁBER, A. N. Os domínios de natureza no Brasil: potencialidades paisagísticas. São Paulo: Ateliê Editora, 2003.

ACIOLY, C. Densidade urbana: um instrumento de planejamento e gestão urbana. Tadução de Claudio Acioly e Forbes Davidson. Rio de Janeiro: Mauad, 1998.

ALCOFORADO, M. J. Aplicação da climatologia ao planejamento urbano. Alguns apontamentos. Finisterra, Lisboa, v. 67-68, 1999, p. 83-94.

ALVES, R de S. Interações entre fatores e elementos do clima no percurso Ponte Nova - Viçosa - Ubá, Zona da Mata Mineira: identificação de diferentes ambientes termohigrométricos. 79f. Dissertação (Monografia em Geografia). Departamento de Artes e Humanidades - Curso de Geografia, UFV, 2015.

ALVES, W. S., MARIANO, Z. F. A influência dos fatores geoecológicos e geourbanos no clima urbano de Iporá-GO: uma análise a partir dos métodos de correlação e regressão linear. Revista Brasileira de Climatologia, Curitiba, Ano 12 - Vol. 19 - Jul/Dez 2016.

AMORIM, M. C. C. T. Climatologia e Gestão do Espaço Urbano. Revista Mercator, Forataleza. Número especial, 2010, p. 71-90.

ASSIS, W. L. O Sistema Clima Urbano do Município de Belo Horizonte da Perspectiva Têmporo-Espacial. 2010. 299 f. Tese (Doutorado) - Curso de Geografia, Instituto de Geociências, Universidade Federal de Minas Gerais, Belo Horizonte, 2010.

CHAPMAN, L.; THORNES, J. Real-Time Sky-View Factor Calculation and Approximation. Journal of Atmospheric and Oceanic Technology - J ATMOS OCEAN TECHNOL. 21. 10.1175/1520-0426(2004).

CORREA, Wesley S.C. Campo térmico e higrométrico da Regional Praia do Canto no município de Vitória (ES) / Wesley de Souza Campos Correa. - 2014.165 f. : il.

COSTA, A. C. L. da; MATTOS A. Estudo da ilha de calor urbana em cidade de grande porte na região Equatorial. X Congresso Brasileiro de Meteorologia, Brasília - DF, 1998.

COLLISCHONN, E.; FERREIRA, C. V. O. O fator de visão do céu e sua influência sobre as características térmico-higrométricas intraurbanas em Pelotas/RS, Brasil. Geographia Meridonalis, 1(1), p.160-178, 2015.

DANNI-OLIVEIRA, I. M. Procedimentos de Aferição de Termômetros Utilizados em Trabalhos de Campo de Climatologia Geográfica. RA EGA (UFPR), Curitiba, v. 6, p. 75-80, 2002. 
DEPARTAMENTO DE HIDROGRAFIA E NAVEGAÇÃO DA MARINHA DO BRASIL (DHN). Disponível em: http://www.dhn.mar.mil.br/.

FERREIRA, G. R.; FIALHO, E. S. Campo térmico x fator de visão do céu: estudo da área central do município de Viçosa-MG em episódios de outono e inverno/2014. Boletim Gaúcho de Geografia, Porto Alegre, v. 34, n. 1, p. 1-25, 2016.

FIALHO, E. S. Ilha de calor em cidade de pequeno porte: um caso de Viçosa, na Zona da Mata Mineira. São Paulo: FFLCH/USP, 2009.

Ilhas de Calor: reflexões acerca de um conceito. Acta Geográfica, Boa Vista, Ed. Esp. Climatologia Geográfica, 2012. pp.61-76.

Unidades Climáticas Urbanas: O caso da Ilha do Governador- RJ. Revista de Ciências Humanas, Viçosa-MG, v. 10, n. 1, p. 26-46, jan./jun., 2010.

FIALHO, E. S.; PAULO, M. L. S. Clima e sítio: a variabilidade termohigronométrica, ao longo do transeto Ponte Nova-Ubá, na Zona da Mata Mineira. In: SILVA, C. A.; FIALHO, E. S.; STEINKE, E. T. (orgs.). Experimentos

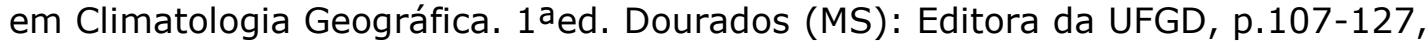
2014.

FIALHO, E. S.; QUINA, R. R.; ALVES, R. S.; MIRANDA, J. D. E. O campo térmico em situação sazonal de verão no município de Viçosa-MG. Revista Geografia(s), Belo Horizonte-MG. Edição Especial, p. 80-98, 2015.

FRESCA, T. M. Centros locais e pequenas cidades: diferenças necessárias. Mercator, Londrina, 2010: dez. p. 75-81

GEIGER, R. Influências das formas do relevo no microclima. In: Manual de microclimatologia: o clima da camada de ar junto ao solo. Lisboa: Fundação Caloust Gulbenkian, 1980. p. 382-474.

HATHWAY, E.A., SHARPLES, S. The interaction of rivers and urban frominmitigating the urban heat island effect: a UK case study. Build Environ. $58,14-22,2012$.

INSTITUTO BRASILEIRO DE GEOGRAFIA E ESTATÍSTICA (IBGE). Disponível em: http:// www.ibge.gov.br. Acessado em: 10 mar. 2017.

INSTITUTO NACIONAL DE METEOROLOGIA - INMET. Disponível em: http://www.inmet.gov.br/portal/.

JUNIOR, E. P. A ilha de calor das cidades: Fatores e Atributos. Boletim Geográfico, ano 34, no 249, IBGE, Rio de Janeiro, 1976.

LANDSBERG, H.E. O clima das cidades. Revista do Departamento de Geografia, São Paulo, v. 18, p. 95-111, may 2011. ISSN 2236-2878. Disponível em: <https://www.revistas.usp.br/rdg/article/view/47269/51005>. Acesso em: 07 sep. 2017. doi:http://dx.doi.org/10.7154/rdg.v0i18.73.

LOPES, L. C. S; JARDIM, C. H. Variações de temperatura e umidade relativa do ar em área urbana e rural durante o segmento temporal de inverno de $2011 \mathrm{em}$ Contagem e Betim (MG). Acta Geografica, v.1, p.205-221, 2012.

LUCENA, A. J. A Ilha de calor na região metropolitana do Rio de Janeiro. Tese (Doutorado em Engenharia Civil) - COPPE/UFRJ. Rio de Janeiro, 2012. $473 f$. 
MARCHI, O. A. M.; CALIJURI, M. L.; COSTA, S. H. G.; LUGÃO, W. G.; SOUZA, P. J. A.; Leitura e Caracterização da Paisagem em Auxílio ao Planejamento da Ocupação Urbana de Ponte Nova - MG. Natureza \& Desenvolvimento, v. 1, n. 1, p. 41-50, 2005.

MARTÍnEZ, J. M. Estudio de la isla de calor de la ciudad de Alicante. Investigaciones Geográficas. Instituto Interuniversitario de Geografia Universidade de Alicante. Dez.2014.

MARTINS, L. A. A Temperatura do Ar em Juiz de Fora - MG : Influência do Sítio e da Estrutura

Urbana. - Departamento de Geografia, Instituto de Geociências e Ciências Exatas/UNESP - Rio Claro, 1996, 168p. Dissertação (Mestrado em Geografia).

MENDONÇA, F. et al. (Organizadores). Clima Urbano. - 2. ed., 2a reimpressão. - São Paulo: Contexto, 2015.

MENDONÇA, F., DANNI-OLIVERIA, I. M. Climatologia: noções básicas e climas do Brasil. Editora Oficina de texto. São Paulo. 2007. 206p.

MOREIRA JÚNIOR, O. As cidades pequenas na região metropolitana de Campinas - SP: Dinâmica demográfica, papéis urbanos e (re)produção do espaço. Tese (Doutorado) - Instituto de Geociência e Ciências Exatas, UNESP, Rio Claro, SP, 2014.

NIMER, E. Climatologia do Brasil. 2 ed. Rio de Janeiro: IBGE, Departamento de Recursos Naturais e Estudos Ambientais, 1989, 422 p.

NUNES, W. A. G. A.; KER, J. C.; SCHAEFER, C. E. G. R.; FERNANDES FILHO, E. I.; GOMES, F. H. Relação solo-paisagem-material de origem e gênese de alguns solos no domínio do "Mar de Morros", Minas Gerais. Revista Brasileira de Ciência do Solo, Viçosa, n. 25, p. 341-354, 2001.

OKE, T. R. Boundary layer climates. London: Metheuen \& Co, 1978.

OLIVEIRA, W. D.; FIALHO, E. S.; ALLOCCA, R. A. A Influência de fatores geomorfológicos na análise da Temperatura da Superfície Terrestre do município de Cariacica-ES. XII ENANPEGE, Porto Alegre, 2017 (ANAIS). Disponível em: http://www.enanpege.ggf.br/2017/

PAULO, M. S. L. O comportamento termo-higrométrico do ar associado à altitude e sistemas sinópticos atuantes no percurso Ponte Nova/Ubá, na Zona da Mata Mineira, no período de novembro de 2013 a agosto de 2014. Banco de monografias Departamento de Geografia da UFV-MG. Viçosa-MG. 2017.

PRADO, L.B; FERNANDES, L.A; FIALHO, E.S.; A variação da temperatura do ar, ao longo do percurso Ponte Nova-Ubá - MG (Brasil) nos anos de 2014 e 2015. Cadernos de Geografia no 37, 2018. Coimbra, FLUC - pp. 55 - 59.

QUINA, R.R. Análise da influência de condicionantes geoambientais e urbanos sobre o comportamento térmico do município de Viçosa-MG, durante o período de verão de 2014/15 e inverno de 2015. Banco de monografias Departamento de Geografia da UFV-MG. Viçosa-MG. 2015.

RIGON, O.;SANT'ANA, T. C. F. OS Papéis das pequenas cidades no contexto atual da rede urbana brasileira: um ensaio sobre a região da AMUSEP. Revista Percurso - NEMO Maringá, v. 5, n. 1 , p. 157- 177, 2013. 
SILVA, L. P. O clima urbano em Pirapozinho - SP: eventos de ilhas de calor urbanas em episódios de verão. Dissertação (Mestrado em Geografia) Universidade Estadual Paulista Júlio de Mesquita Filho. 2017.

STEFFENS, A.C.; CINTIA, M.; HERNÁNDEZ, J.; NAVARRETTE, G.; La Isla de calor en estival em Temuco, Chile. Papeles de Geografía, 33, p. 49-60. (2001),

UGEDA JÚNIOR, J. C. Clima urbano e planejamento na cidade de Jales-SP. Tese (Doutorado). Presidente Prudente: [s.n], 2012; 383 f. : il 